\title{
Taurocholate Induces Biliary Differentiation of Liver Progenitor Cells Causing Hepatic Stellate Cell Chemotaxis in the Ductular Reaction
}

\section{Role in Pediatric Cystic Fibrosis Liver Disease}

\author{
Katarzyna N. Pozniak, ${ }^{* \dagger}$ Michael A. Pearen, ${ }^{*}$ Tamara N. Pereira, ${ }^{*}$ Cynthia S.M. Kramer, ${ }^{*}$ Priyakshi Kalita-De Croft, ${ }^{*}$ \\ Sujeevi K. Nawaratna, ${ }^{\ddagger}$ Manuel A. Fernandez-Rojo, ${ }^{\dagger \dagger}$ Geoffrey N. Gobert, ${ }^{\ddagger \S}$ Janina E.E. Tirnitz-Parker, ${ }^{\top \|}$ John K. Olynyk, ${ }^{\top * * \dagger \dagger}$ \\ Ross W. Shepherd, * Peter J. Lewindon, ${ }^{* \dagger+\ddagger}$ and Grant A. Ramm ${ }^{\star \dagger}$
}

\begin{abstract}
From the Hepatic Fibrosis Group* and the Molecular Parasitology Group, ${ }^{\ddagger}$ QIMR Berghofer Medical Research Institute, Brisbane, Queensland, Australia; the Faculty of Medicine ${ }^{\dagger}$ and the Department of Gastroenterology, ${ }_{\ddagger \neq}^{\ddagger}$ The University of Queensland, Brisbane, Queensland, Australia; the School of Biological Sciences, ${ }^{\circledR}$ Queen's University Belfast, Belfast, United Kingdom; the School of Biomedical Sciences, ${ }^{\top}$ CHIRI Biosciences, Curtin University, Bentley, Western Australia, Australia; the School of Medicine and Pharmacology," University of Western Australia, Fremantle, Western Australia, Australia; the Department of Gastroenterology \& Hepatology, ** Fiona Stanley and Fremantle Hospitals, Perth. Western Australia, Australia; and the Faculty of Health Sciences, ${ }^{\dagger \dagger}$ Edith Cowan University, Perth, Western Australia, Australia
\end{abstract}

\author{
Accepted for publication \\ August 11, 2017. \\ Address correspondence to \\ Grant A. Ramm, Ph.D., Head, \\ Hepatic Fibrosis Group, QIMR \\ Berghofer Medical Research \\ Institute, PO Royal Brisbane \\ and Women's Hospital, Bris- \\ bane, Queensland 4029, Aus- \\ tralia. E-mail: grant.ramm@ \\ qimrberghofer.edu.au.
}

\begin{abstract}
Cystic fibrosis liver disease (CFLD) in children causes progressive fibrosis leading to biliary cirrhosis; however, its cause(s) and early pathogenesis are unclear. We hypothesized that a bile acid-induced ductular reaction (DR) drives fibrogenesis. The DR was evaluated by cytokeratin-7 immunohistochemistry in liver biopsies, staged for fibrosis, from 60 children with CFLD, and it demonstrated that the DR was significantly correlated with hepatic fibrosis stage and biliary taurocholate levels. To examine the mechanisms involved in DR induction, liver progenitor cells (LPCs) were treated with taurocholate, and key events in DR evolution were assessed: LPC proliferation, LPC biliary differentiation, and hepatic stellate cell (HSC) chemotaxis. Taurocholate induced a time-dependent increase in LPC proliferation and expression of genes associated with cholangiocyte differentiation (cytokeratin 19, connexin 43, integrin $\beta 4$, and $\gamma$-glutamyltranspeptidase), whereas the hepatocyte specification marker HNF4 $\alpha$ was suppressed. Functional cholangiocyte differentiation was demonstrated via increased acetylated $\alpha$ tubulin and SOX9 proteins, the number of primary cilia ${ }^{+}$LPCs, and increased active $\gamma$-glutamyltranspeptidase enzyme secretion. Taurocholate induced LPCs to release MCP-1, MIP1 $\alpha$, and RANTES into conditioned medium causing HSC chemotaxis, which was inhibited by anti-MIP1 $\alpha$. Immunofluorescence confirmed chemokine expression localized to $C K 7^{+}$DR and LPCs in CFLD liver biopsies. This study suggests that taurocholate is involved in initiating functional LPC biliary differentiation and the development of the DR, with subsequent induction of chemokines that drive HSC recruitment in CFLD. (Am J Pathol 2017, 187: 2744-2757; https://doi.org/10.1016/j.ajpath.2017.08.024)
\end{abstract}

Cystic fibrosis-associated liver disease (CFLD) is characterized by indolent intrahepatic cholestasis that usually manifests by early adolescence. ${ }^{1}$ Cystic fibrosis (CF) is caused by a defect in the gene coding for the cystic fibrosis transmembrane conductance regulator (CFTR) which, among other functions, maintains the flow of bile in contact with cholangiocytes by facilitating the movement of water
Supported by National Health and Medical Research Council (NHMRC) of Australia grant APP1048740 (G.A.R., P.J.L., R.W.S.), Practitioner Fellowship from the NHMRC of Australia grant APP1042370 (J.K.O.), and Senior Research Fellowship from the NHMRC of Australia grant APP1061332 (G.A.R.).

K.N.P., M.A.P., and T.N.P. contributed equally to this work.

Disclosures: None declared. 
and bicarbonate ions into bile. Abnormal ion/water transport leads to inspissated bile and cholestasis with focal fibrosing destruction of intrahepatic bile ducts. ${ }^{2}$ The resulting pattern of injury is focal biliary cirrhosis for which there is no known treatment and which may progress to cause portal hypertension, multilobular biliary cirrhosis, and liver failure. However, only $10 \%$ of children with CF will develop portal hypertension and cirrhosis, a higher prevalence than the overall CF population, indicating a strong survival disadvantage. The cause and mechanism of this variable presentation and severity of pathology are not known. ${ }^{3}$

The ductular reaction (DR) is characterized by the expansion of a population of bipotential liver progenitor cells (LPCs) which can differentiate toward the cholangiocyte lineage into reactive bile ductules, as well as intermediate hepatocytes. ${ }^{4,5}$ LPCs have been proposed by some groups to reside within periportal areas associated with the canals of Hering, ${ }^{6}$ although their precise cellular origin is the subject of ongoing controversy. ${ }^{7}$ LPC expansion is thought to mediate a secondary pathway of liver regeneration, which occurs when the process of hepatocyte replication is overwhelmed in chronic liver disease. ${ }^{8}$ In cholestasis, this expansion is postulated to be a futile attempt to drain excess bile via the formation of additional bile ductules and to replace damaged hepatocytes. ${ }^{9}$ The DR is observed along with activation of hepatic stellate cells (HSCs) and an increase in hepatic fibrosis, which is seen in adult liver diseases that show periportal damage in cholestatic liver diseases, ${ }^{5,10}$ as well as other conditions such as viral hepatitis $\mathrm{A}^{11}$ and $\mathrm{C},{ }^{12} H F E$ associated hemochromatosis, ${ }^{13}$ alcoholic and nonalcoholic fatty liver diseases, ${ }^{14}$ and posttransplant HCV. ${ }^{15}$ This has led to the hypothesis that the two processes of LPC expansion and HSC activation with the resultant DR and fibrosis, respectively, are closely related. Although histological evidence of a DR has previously been demonstrated in children with extrahepatic biliary atresia, ${ }^{16,17}$ the potential role of LPCs driving HSC activation and fibrosis via development of the DR has not previously been assessed in CFLD.

Bile acids are synthesized in hepatocytes from cholesterol and are usually conjugated to taurine or glycine to form bile salts and secreted into the bile canaliculi. These bile secretions flow into bile ducts, where they are stabilized by bicarbonate ions and water secreted by cholangiocytes as they are excreted from the liver into the gall bladder. They aid lipid digestion in the duodenum by forming micelles. However, their partial hydrophobic nature, which is essential in forming micelles, also makes them toxic to the liver in higher concentrations. ${ }^{18}$ The bile salt composition within bile is altered in children with CFLD, as we have previously shown, ${ }^{19}$ and is comparable to that of mice following bile duct ligation. ${ }^{20}$ In particular, the hydrophobic bile salt, taurocholate is significantly increased in both bile and serum of children with CFLD. ${ }^{21}$ Taurocholate and other bile salts are able to up-regulate the expression of inflammatory genes in the liver. ${ }^{22}$ Taurocholate has also been shown to stimulate cytokine secretion from cholangiocytes ${ }^{23}$ and hepatocytes, ${ }^{21}$ which induce transdifferentiation of portal fibroblasts $^{24}$ as well as facilitating HSC migration. ${ }^{21,25}$ We previously demonstrated that taurocholate induced the expression of monocyte chemotaxis protein-1 (MCP-1) in normal hepatocytes, and that MCP-1 produced by cholestatic hepatocytes from bile duct-ligated rats induced the chemotaxis of HSCs. ${ }^{21}$ Markedly increased expression of MCP-1 was observed in hepatocytes and cholangiocytes in the liver of children with cholestatic liver diseases. ${ }^{21}$

In this study, we investigated whether the DR is present in the liver of children with CFLD and examined mechanisms associated with its induction and role in fibrogenesis. We compared the severity of the DR in CFLD liver biopsies with those from other, more aggressively cholestatic pediatric liver disease and then specifically examined a potential mechanism of DR induction in CFLD through investigating the relationship between biliary taurocholate concentrations and the DR in liver biopsies from children with CFLD in vivo. We then used in vitro cell culture models and ex vivo liver slices to investigate the in vivo observed effects of elevated taurocholate on LPC differentiation, the secretion of chemokines by LPCs, and their chemotactic effects on HSCs in driving hepatic fibrogenesis.

\section{Materials and Methods}

\section{Patient Specimens}

This study is part of a long-term prospective cohort study of patients with CFLD, identified and referred from the CF Clinic, Royal Children's Hospital, Brisbane, that is previously well documented. ${ }^{19,21,26-28}$ CFLD was defined as two of the following: i) hepatomegaly with or without splenomegaly; ii) persistent ( $>6$ months) elevation of serum alanine aminotransferase ( $>1.5 \times$ upper limit normal); and iii) abnormal liver ultrasound (abnormal echogenicity or nodular edge). Those with liver synthetic dysfunction or a history of hepatobiliary surgery were excluded. The study conformed to the ethical guidelines of the 1975 Declaration of Helsinki and was approved by the ethics committees of the Royal Children's Hospital, Brisbane, and the QIMR Berghofer Medical Research Institute. Informed consent was obtained from parents or patients.

Liver tissue was available from 60 children with CFLD (age, $11.8 \pm 4.5$ years). For comparison with other pediatric cholestatic liver diseases, liver tissue was also available from three infants with biliary atresia (age, $1.2 \pm 1.4$ years), five with idiopathic neonatal hepatitis (age, $3.4 \pm 3.6$ years), as well as four pediatric donor liver controls (age, $6.8 \pm 4.5$ years). Bile was available from 7 children with CFLD.

\section{Immunohistochemistry}

Formalin-fixed, paraffin-embedded liver sections were subjected to heat antigen retrieval, before exposure to 3\% hydrogen peroxide in phosphate-buffered saline and Background Sniper (Biocare Medical, Pacheco, CA). Sections were then stained with primary antibody: mouse anti-human 
Table 1 List of qPCR Primers

\begin{tabular}{|c|c|c|c|}
\hline Primers & NCBI accession & Forward & Reverse \\
\hline $\operatorname{Tgf}-\beta 1$ & NM_021578 & $5^{\prime}$-GCTTCAGCTCCACAGAGAAGA-3' & $5^{\prime}-$ CCAGGCTCCAAATGTAGGGG-3' \\
\hline$C \times 43$ & NM_010288 & 5'-AGCTAGGCGGCAAAAGTAGG-3' & 5'-АCTCACTCATGTATACAGAACCAT-3' \\
\hline Ck19 & NM_008471 & 5'-GTCGAGGGAGGGGTTAGAGT-3' & 5'-CCATCTGAGCTACCAGCGAG- $3^{\prime}$ \\
\hline Ggt1 & NM_008116 & $5^{\prime}$-CAGCACCACAGGAAAAGTTGAG-3' & $5^{\prime}$-ACGGATTTCACCAGGGACAG- $3^{\prime}$ \\
\hline $\operatorname{Itg} b 4$ & NM_001005608 & 5'-GACCTATGAAGAAGGTGCTC-3' & $5^{\prime}$-GGCTCAGATGCGTGCCATAG-3' \\
\hline Sox9 & NM_011448 & 5'-AGTACCCGCATCTGCACAAC- $3^{\prime}$ & 5'-TACTTGTAATCGGGGTGGTCT-3' \\
\hline Rantes & NM_031116 & 5'-TGCCCACGTGAAGGAGTATTTTTA-3' & 5'-TGGCGGTTCCTTCGAGTGACAA-3' \\
\hline$P d g f b$ & NM_011057 & 5'-ATCCGCTCCTTTGATGATCT-3' & 5'-GAGCTTTCCAACTCGACTCC-3' \\
\hline $\operatorname{Mip} 1 \alpha$ & NM_011337 & 5'-CTGCCCTTGCTGTTCTTCTC-3' & $5^{\prime}$-CTTGGACCCAGGTCTCTTTG-3' \\
\hline Mcp-1 & NM_011333 & 5'-GCTGACCCCAAGAAGGAATG-3' & 5'-GTGCTTGAGGTGGTTGTGGA-3' \\
\hline hCor1 & NM_001295 & 5'-CCTGCTGACGATTGACAGGTA-3' & 5'-TTGGAAAAGTATAAGCCTGGCAT-3' \\
\hline
\end{tabular}

Information on the primers can be found by their ascension numbers at the NCBI Nucleotide database: https://www.ncbi.nlm.nih.gov/nuccore. qPCR, real-time quantitative PCR.

CK7 monoclonal antibody (dilution 1:100; Dako, Glostrup, Denmark), secondary antibody: rabbit anti-mouse biotinylated IgG (dilution 1:400, Dako), with detection using a streptavidin-biotin/horseradish peroxidase kit (Dako) and chromogenic substrate 3,3'-diaminobenzidine tetrahydrochloride (Sigma-Aldrich, St. Louis, MO), and counterstained with hematoxylin. Digital images were captured using Aperio ScanScope XT slide scanner (Leica Biosystems, Buffalo Grove, IL) under $\times 20$ magnification at 0.5 $\mu \mathrm{m} /$ pixel. Image analysis was performed using Aperio Positive Pixel Count algorithm software version 9.1. Positively stained cells were counted, normalized to the total section area, and results correlated with Scheuer's hepatic fibrosis staging.

\section{Biliary Taurocholate Measurement}

Taurocholate concentration was measured in endoscopic bile samples available from seven patients with CFLD, as previously described. ${ }^{21}$ Liver biopsies were processed for histochemical CK7 quantification as above. All patients had histological evidence of hepatic fibrosis. Biliary taurocholate levels were correlated with CK7 quantification.

\section{Culture of Cell Lines and in Vitro Studies}

The murine LPC line PIL-2 ${ }^{29}$ was cultured in Williams' E medium containing $2 \mathrm{mmol} / \mathrm{L}$ glutamine, penicillin (100 U/ $\mathrm{mL})$, streptomycin $(100 \mu \mathrm{g} / \mathrm{mL})$, insulin $(10 \mu \mathrm{g} / \mathrm{mL})$, epidermal growth factor $(10 \mathrm{ng} / \mathrm{mL})$, insulin-like growth factor II (30 ng/mL), and 10\% fetal bovine serum (FBS). The human HSC line LX-2 was cultured in Dulbecco's modified Eagle's medium with $2 \mathrm{mmol} / \mathrm{L}$ glutamine, penicillin $(100 \mathrm{U} / \mathrm{mL})$, streptomycin $(100 \mu \mathrm{g} / \mathrm{mL})$, and $2 \%$ FBS. PIL-2 cells were treated with taurocholate at 0 to $300 \mu \mathrm{mol} /$ $\mathrm{L}$ concentration to establish a dose-response, with an optimal concentration of $150 \mu \mathrm{mol} / \mathrm{L}$ taurocholate chosen for all in vitro and ex vivo experiments, as previously described. ${ }^{21}$ For differentiation assays, cells were lysed 1 to 4 days after taurocholate treatment. LPC differentiation was assessed using real-time quantitative PCR (qPCR) and/or Western blot analysis evaluating markers for cholangiocyte (connexin 43,Cx43; cytokeratin 19, Ck19; integrin $\beta 4$, Itgb4; $\gamma$-glutamyl transpeptidase $1, G g t l ;$ epithelial cell adhesion molecule, EpCam; SYR-related HMG box transcription factor 9, Sox9) and hepatocyte (albumin; hepatocyte nuclear factor $4 \alpha, H n f 4 \alpha$ ) phenotype.
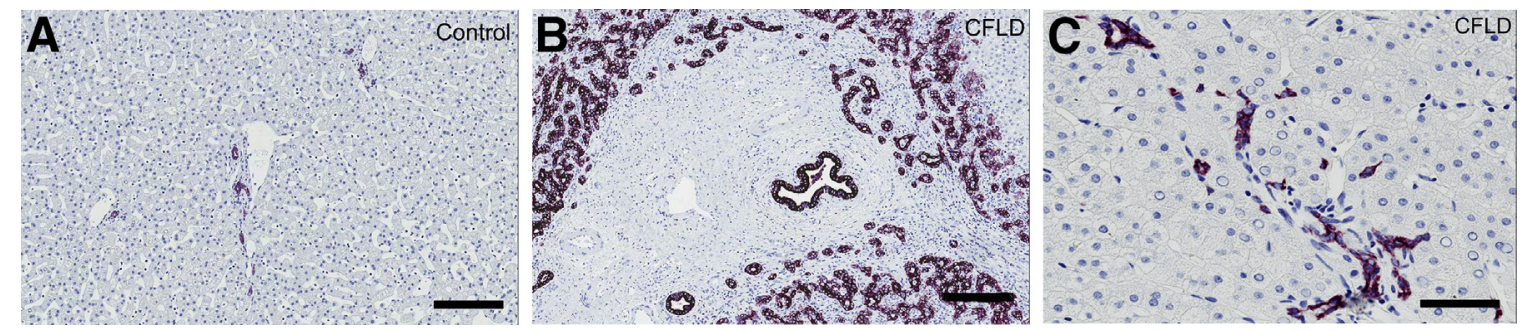

Figure 1 Evidence of the ductular reaction (DR) in cystic fibrosis liver disease (CFLD). Immunohistochemistry for CK7 expression in the liver of a donor control subject (A) and a child with CFLD (B and $\mathbf{C})$. The CFLD patient shows a marked DR (B) and numerous single CK $7^{+}$liver progenitor cells adjacent to areas of DR (C). Scale bars: $200 \mu \mathrm{m}(\mathbf{A}) ; 160 \mu \mathrm{m}(\mathbf{B}) ; 60 \mu \mathrm{m}$ (C). Original magnification: $\times 10(\mathbf{A}) ; \times 8(\mathbf{B}) ; \times 40$ (C). 

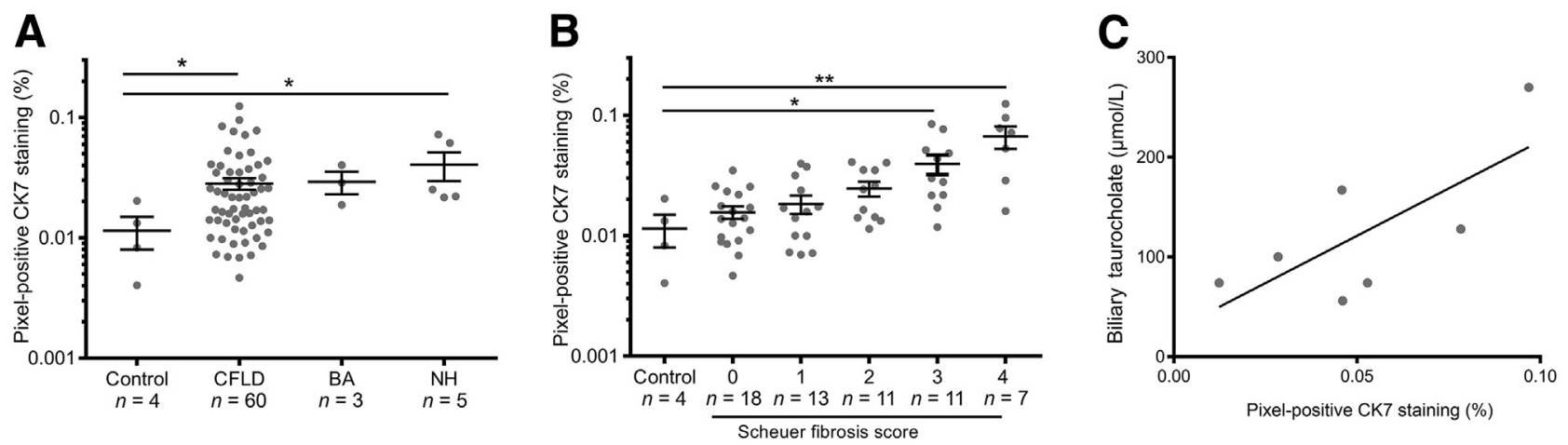

Figure 2 Assessment of the ductular reaction in cystic fibrosis liver disease (CFLD) and other pediatric cholestatic liver diseases. A: CK7 expression in three pediatric cholestatic liver diseases: CFLD, biliary atresia (BA), and idiopathic neonatal hepatitis (NH) versus donor control livers. Statistical calculations were performed using an analysis of variance with Kruskal-Wallis test. B: Correlation between CK7 expression and hepatic fibrosis stage in livers of children with CFLD (Spearman $r=0.59, P<0.0001$ ). Statistical calculations were performed using an analysis of variance with Kruskal-Wallis test. C: Correlation between hepatic CK7 expression and biliary taurocholate levels in children with CFLD (Pearson $r^{2}=0.528$; one-tailed $P=0.0283$ ). Data are expressed as means \pm SEM. $n=7$ (C). ${ }^{*} P<0.05,{ }^{*} P<<0.01$.

\section{qPCR for LPC Differentiation Marker and Chemokine mRNA Expression}

RNA was extracted from both untreated and taurocholatetreated PIL-2 cells using the RNeasy kit (Qiagen, Hilden,
Germany), and $1 \mu \mathrm{g}$ was reverse transcribed into cDNA using SensiFast (Bioline, Taunton, MA). qPCR was performed on a Bio-Rad CFX96 Real-Time PCR Detection System (Bio-Rad, Hercules, CA) with HPRT used as the reference gene. Primers are listed in Table 1.

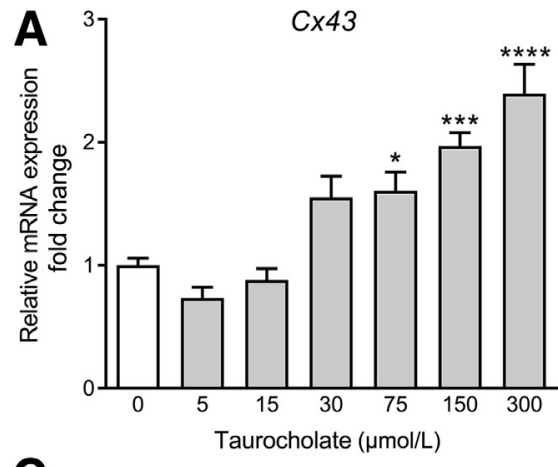

C

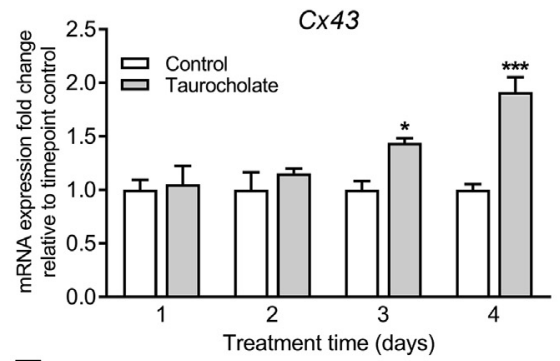

E

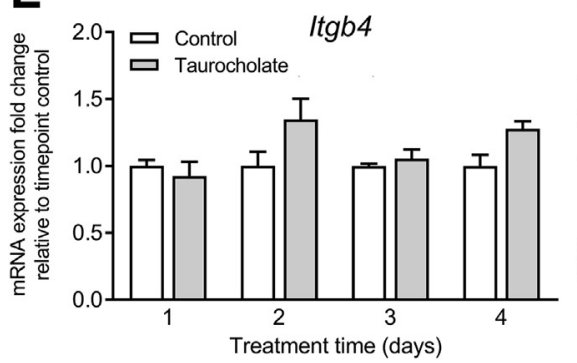

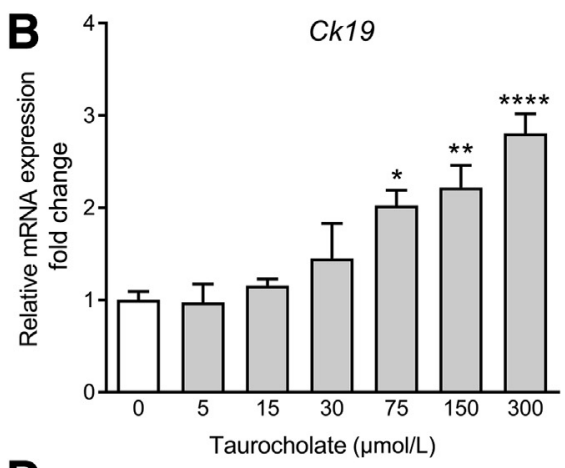

D

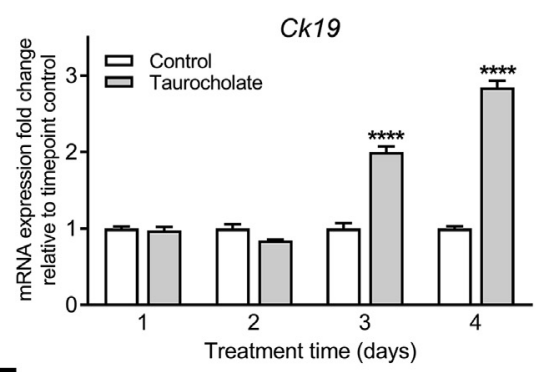

$\mathbf{F}$

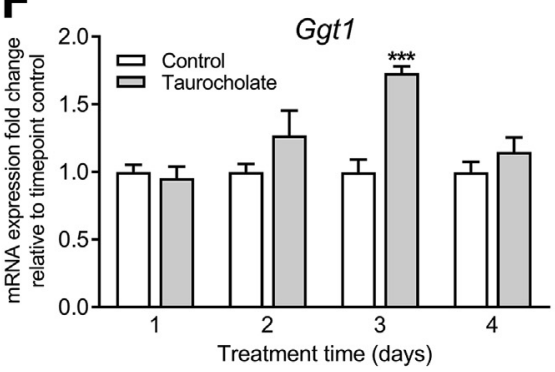

Figure 3 Taurocholate induces markers of cholangiocyte differentiation in liver progenitor cells. Taurocholate ( 0 to $300 \mu \mathrm{mol} / \mathrm{L}$ ) induced a dosedependent increase in mRNA expression of cholangiocyte markers $C \times 43$ (analysis of variance, $P<0.0001$ ) (A) and $C_{k 19}$ (analysis of variance, $P<0.0001)(B)$ in PIL-2 cells $(n=4)$. Dunnett's multiple comparisons test was performed relative to untreated cells. PIL-2 cells treated with $150 \mu \mathrm{mol} / \mathrm{L}$ taurocholate for up to 4 days induced a timedependent increase in the mRNA expression of cholangiocyte markers $\mathrm{C} \times 43$ (C) (analysis of variance, $P<0.0001$ ), CK19 (D) (analysis of variance, $P<0.0001$ ), Itgb4 (E) (analysis of variance, $P=0.029$ ), and Ggt1 (F) (analysis of variance, $P=0.001$ ), expressed relative to vehicle control at each time point. Sidak's multiple comparisons test was used for comparison at individual time points of taurocholate treatment. Data are expressed as means \pm SEM. $n=4$. ${ }^{*} P<0.05,{ }^{*} P<<0.01$, $* * * P<0.001$, and $* * * * P<0.0001$. versus control 

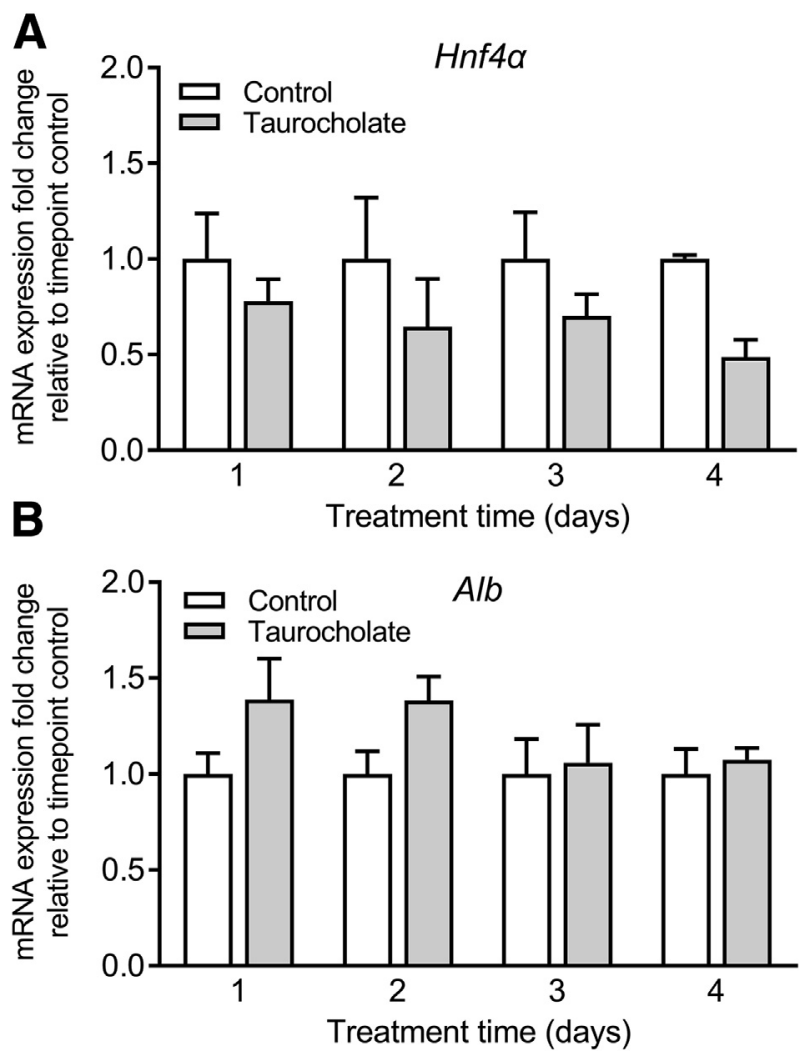

Figure 4 The effect of taurocholate on markers of hepatocyte differentiation in liver progenitor cells. PIL-2 cells treated with $150 \mu \mathrm{mol} / \mathrm{L}$ taurocholate for up to 4 days resulted in a time-dependent decrease in mRNA expression for the hepatocyte marker hepatocyte nuclear factor $4 \alpha$ (Hnf $4 \alpha$; analysis of variance, $P=0.0255)(\mathbf{A})$, expressed relative to vehicle control at each time point, although there was no apparent effect on albumin $(A l b)$ expression (B). Data are expressed as means \pm SEM. $n=4$.

\section{MTT Cell Proliferation Assay}

Cell proliferation was measured over a 2-hour period at 1 to 4 days following treatment of PIL-2 cells with $150 \mu \mathrm{mol} / \mathrm{L}$ sodium taurocholate using the method of Alley et al. ${ }^{30}$ Absorbance was measured at $570 \mathrm{~nm}$ with a $620-\mathrm{nm}$ reference filter.

\section{Western Blot Analysis}

Cell lysates were prepared from PIL-2 cells disrupted in RIPA buffer with Complete EDTA-free protease inhibitors (Roche, Basel, Switzerland). Lysates were resolved on $10 \%$ SDS-PAGE gels as described in Laemmli et $\mathrm{al}^{31}$ and transferred to polyvinyl difluoride membranes (ImmobilonFL; Merck Millipore, Billerica, MA). Membranes were probed with anti-CK19 (ab15463; dilution 1:2000; Abcam, Cambridge, MA); anti-SOX9 (AB5535; dilution 1:1000; Merck Millipore); anti-HNF4 $\alpha$ (Santa Cruz sc6556; dilution 1:1000; Santa Cruz Biotechnology, Dallas, TX); antiacetylated $\alpha$-tubulin (T7451; dilution 1:1000; SigmaAldrich); with anti- $\beta$-actin used to detect the $\beta$-actin loading control (dilution 1:2000; Cell Signaling
Technology, Danvers, MA), in TBST LI-COR Odyssey blocking buffer (LI-COR, Lincoln, NE). Blots were probed with an anti-mouse $680 \mathrm{RD}$ or anti-rabbit $800 \mathrm{CW}$ secondary at dilution 1:20,000 in TBST LI-COR Odyssey blocking buffer. Secondary localization was detected with the LICOR Odyssey CLx Infrared Imaging System. Band quantification was performed using Image Studio Lite version 5.2 (LI-COR).

\section{Immunofluorescence}

To examine primary cilia, PIL-2 cells were grown on glass coverslips to $60 \%$ to $80 \%$ confluence and treated for 3 days with and without $150 \mu \mathrm{mol} / \mathrm{L}$ taurocholate, and were then serum-starved overnight before fixation. Cells were placed at $4{ }^{\circ} \mathrm{C}$ for 30 minutes to destabilize microtubules and then fixed in $4 \%$ paraformaldehyde for 10 minutes. Cells were permeabilized with $0.5 \%$ Triton X-100, blocked with $5 \%$ bovine serum albumin, and probed with mouse antiacetylated $\alpha$-tubulin (dilution 1:600; Sigma-Aldrich) and rabbit anti- $\gamma$-tubulin (dilution 1:400; Sigma-Aldrich) antibodies overnight in phosphate-buffered saline with $0.05 \%$ Tween 20 with $1 \%$ bovine serum albumin. Primary binding was probed with AlexaFluor 594 donkey anti-rabbit (Invitrogen, Carlsbad, CA) and AlexaFluor 594 goat anti-mouse (Invitrogen) at dilution 1:500 for 1 hour in phosphatebuffered saline with $0.05 \%$ Tween 20 with $1 \%$ bovine serum albumin. Images were captured with a Zeiss AxioScop2 (Carl Zeiss, Oberkochen, Germany). Quantification of acetylated $\alpha$-tubulin spots was performed using Particle Analysis in ImageJ software version 1.50i (NIH, Bethesda, MD; http://imagej.nih.gov/ij).

To identify the cellular source of HSC chemokines in liver biopsies from children with CFLD, we performed dual immunofluorescence for chemokines MCP-1; regulated upon activation, normal $\mathrm{T}$ cell expressed and secreted

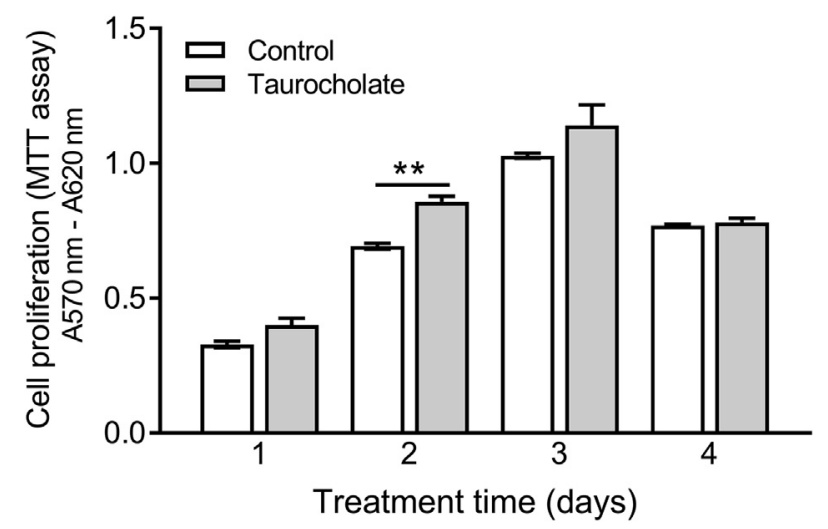

Figure 5 Liver progenitor cell proliferation is induced by taurocholate. Taurocholate $(150 \mu \mathrm{mol} / \mathrm{L})$ induced a time-dependent increase in cell proliferation (analysis of variance, $P=0.0003$ ) in PIL-2 cells treated for 0 to 4 days, as assessed using an MTT assay. Sidak's multiple comparisons test was performed for treatment comparison at individual time points. Data represent means \pm SEM. $n=4$. ${ }^{* *} P<0.01$. A570 nm, absorbance at $570 \mathrm{~nm} ; \mathrm{A} 620 \mathrm{~nm}$, absorbance at $620 \mathrm{~nm}$. 
A

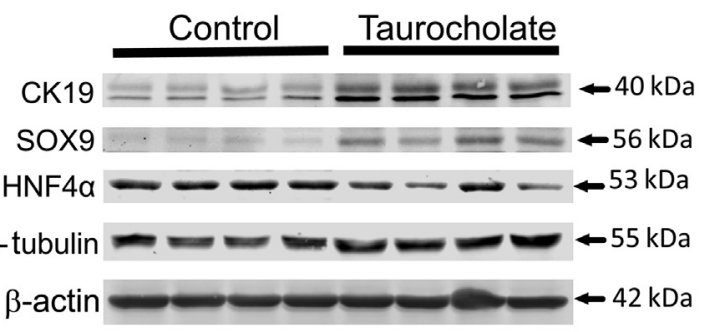

B

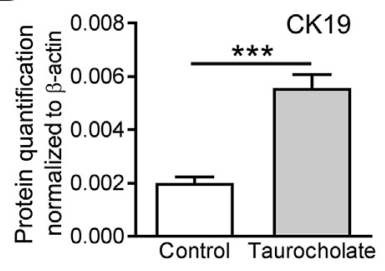

C

D
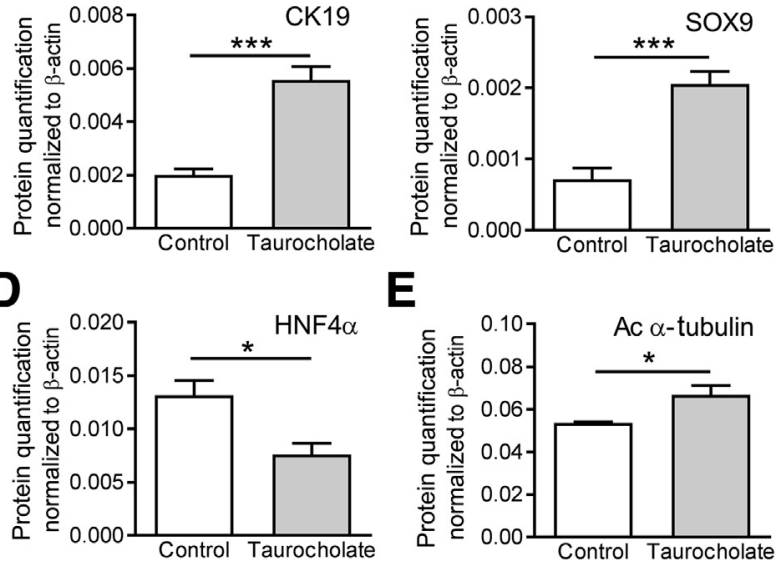

$\mathbf{E}$

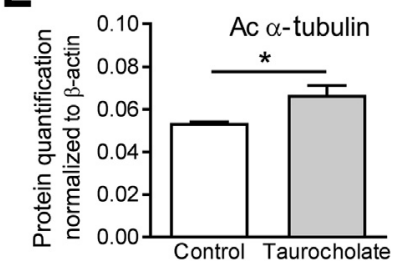

Figure 6 Taurocholate induces functional characteristics of biliary differentiation in liver progenitor cells in vitro at the protein level. PIL-2 cells were treated with $150 \mu \mathrm{mol} / \mathrm{L}$ taurocholate for 4 days. A: Western blot analysis revealed an increased expression of CK19 and S0X9 proteins, whereas $\mathrm{HNF} 4 \alpha$ protein expression was decreased, relative to the $\beta$-actin loading control. Increased expression of acetylated $\alpha$-tubulin protein relative $\beta$-actin was also observed. B-E: Band quantification from infrared imaging demonstrated that taurocholate induced statistically significant increases in CK19 (B), S0X9 (C), and acetylated $\alpha$-tubulin (E), whereas conversely, HNF4 $\alpha$ protein expression was significantly decreased (D). Data are expressed as means \pm SEM. $n=4(\mathbf{A}-\mathbf{E})$. ${ }^{*} P<0.05,{ }^{* *} P<0.001$ ( $t$-test). $A C$, acetylated; $\mathrm{kDa}$, kilodalton.

(RANTES); or macrophage inflammatory protein $1 \alpha$ (MIP1 $\alpha$ ), together with the LPC/DR marker, CK7. Primary antibodies used were: mouse anti-CK7 monoclonal antibody (dilution 1:150; Abcam), goat anti-human MCP-1 polyclonal antibody (dilution 1:8; R\&D Systems, Minneapolis, $\mathrm{MN}$ ), goat anti-human CCL5/RANTES polyclonal antibody (dilution 1:83; R\&D Systems), goat anti-human MIP1 $\alpha$ (dilution 1:50; R\&D Systems), incubated overnight at $4^{\circ} \mathrm{C}$ followed by a 30 -minute incubation step at room temperature with donkey anti-mouse IgG AlexaFluor 555 (dilution 1:300; Invitrogen) and donkey anti-goat IgG AlexaFluor 488 (dilution 1:300; Molecular Probes, Eugene, OR). Sections were mounted in Prolong Gold (Invitrogen) with DAPI and examined by confocal microscopy (Zeiss 780NLO).

\section{Ex Vivo Liver Slice Studies}

Precision-cut liver slices were made as previously described. ${ }^{32}$ A minimum of three liver slices each from three separate C57BL6 WT mice for each time point and each treatment group, were incubated in Williams' E medium containing $2 \mathrm{mmol} / \mathrm{L}$ glutamine, penicillin $(100 \mathrm{U} / \mathrm{mL})$, streptomycin $(100 \mu \mathrm{g} / \mathrm{mL})$, and $10 \%$ FBS at $37^{\circ} \mathrm{C}$ for 2 and 4 days with and without $150 \mu \mathrm{mol} / \mathrm{L}$ taurocholate. Conditioned medium was examined for GGT enzyme activity. Slices were harvested for mRNA quantitation using qPCR.

\section{$\gamma$-Glutamyl Transpeptidase Activity Assay}

GGT activity was determined from in vitro cell cultures and ex vivo liver slice conditioned media using the GGT activity colorimetric assay kit (Sigma-Aldrich). Protein for normalization was measured using the Pierce BCA protein assay (Thermo Fisher Scientific, Waltham, MA).

\section{Quantification of Cytokine Protein Secretion from LPCs with or without Taurocholate}

Chemokines MCP-1, MIP1 $\alpha$, and RANTES, released from LPCs, were quantified using the Cytokine Bead Array (BD Biosciences, San Jose, CA), according per manufacturer's protocol. The concentrations of transforming growth factor$1 \beta$ (TGF- $\beta 1$ ) and platelet-derived growth factor-BB (PDGFB) secreted by LPCs were determined by enzymelinked immunosorbent assay (R\&D Systems).

\section{Chemotaxis Assays}

Induction of HSC chemotaxis via taurocholate treatment of LPCs was examined by measuring cell migration through 8$\mu \mathrm{m}$ 24-well cell culture inserts (Greiner Bio-One, Kremsmünster, Austria) in modified Boyden chambers. Assays were performed using $0.5 \times 10^{6} \mathrm{LX}-2$ cells (serum starved overnight) per $\mathrm{mL}$ within the insert, and the inserts were placed suspended within test medium. Test medium was either normal nonconditioned serum-free Williams' E medium or conditioned medium from LPCs with and without taurocholate. Chemokine neutralization was performed by pretreating conditioned medium with $2.5 \mu \mathrm{g} / \mathrm{mL}$ anti-mouse MCP-1 (AF-479-NA), $1 \mu \mathrm{g} / \mathrm{mL}$ anti-mouse MIP1 $\alpha$ (AF-450-NA), or $1 \mu \mathrm{g} / \mathrm{mL}$ anti-mouse RANTES (AF478) polyclonal neutralization antibodies (R\&D Systems), 1 hour before the assay. Testing of MIP1 $\alpha$ as chemokine used murine (40-337; ProSci, Poway, CA) or human (40-364; ProSci) recombinant purified MIP1 $\alpha$ proteins. Blocking of the CCR5 receptor used the neutralization/blocking antibody MAB182 (R\&D Systems) applied to the LX-2 cells within the Boyden chamber insert for 1 hour before the assay at an insert concentration of $20 \mu \mathrm{g} / \mathrm{mL}$. Chemotaxis assay were performed for 24 hours, and migrated cells on the underside of the insert membrane were then stained with Cell Stain (90144; Merck Millipore), treated with Extraction Buffer (90145; Merck Millipore) and absorbance measured at $560 \mathrm{~nm}$. Results from separate experimental replicates were normalized to the mean absorbance of control samples (nonconditioned serum-free assay medium and FBS positive control). 

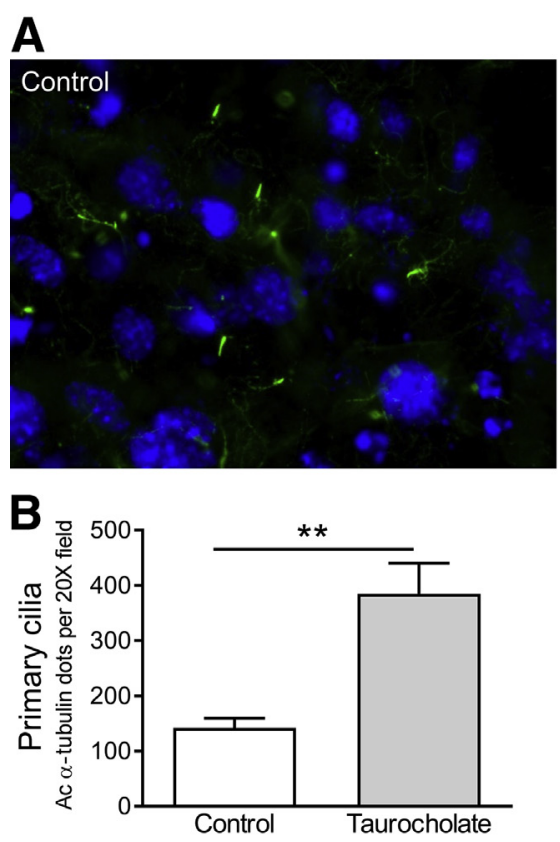
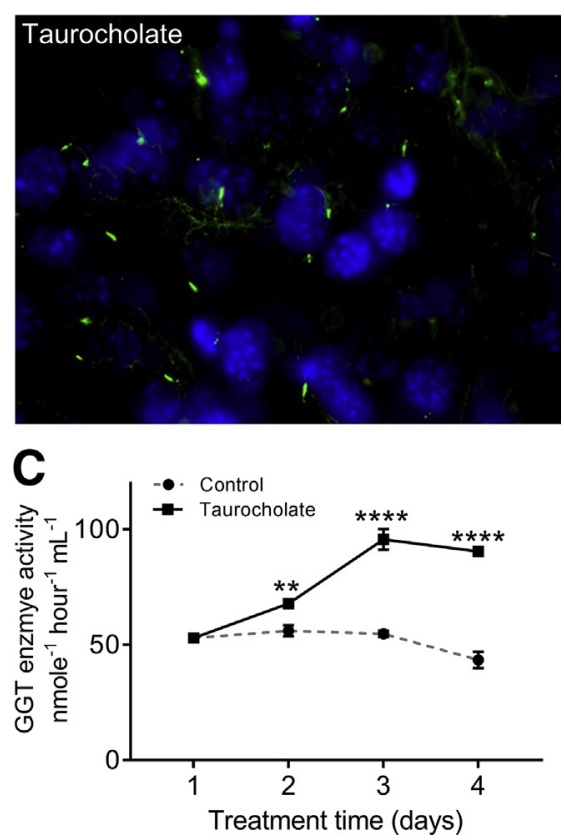

Figure 7 Taurocholate induces morphological and biochemical characteristics of functional biliary differentiation in liver progenitor cells in vitro. A and B: PIL-2 cells grown on coverslips were treated with $150 \mu \mathrm{mol} / \mathrm{L}$ taurocholate for 3 days versus untreated controls, and serum starved overnight to enhance cilia production. Cells were examined for the presence of primary cilia via expression of acetylated $\alpha$-tubulin (green). Cells were also labelled with the nuclear strain (DAPI). These images show an increase in the number of primary cilia in response to taurocholate $(\mathbf{A}$, right panel) versus control ( $\mathbf{A}$, left panel), which when the individually stained spots/lines of fluorescence were quantified, show a statistically significant 2.4-fold increase (B) using the $t$-test. C: Taurocholate $(150 \mu \mathrm{mol} / \mathrm{L}, 1$ to 4 days $)$ induced a time-dependent increase in GGT enzyme activity (represented as nmole of $\mathrm{p}$-nitroanilide per hour/ $\mathrm{mL}$ ) in conditioned media from PIL-2 cells (analysis of variance, $P<0.0001)$. Sidak's multiple comparisons test was performed for comparison at individual time points of taurocholate treatment. Data are expressed as means \pm SEM. $n=3$ (A and B),$n=4$ (C). ${ }^{* *} P<0.01,{ }^{* * *} P<0.0001$ versus control. Original magnification, $\times 100$.

\section{Statistical Analysis}

Results are presented as means \pm SEM. Statistical analysis was performed with GraphPad Prism software version 6 (GraphPad Software, La Jolla, CA). The following tests were performed: For immunohistochemical analysis, the $U$ test and one-way nonparametric analysis of variance with Kruskal-Wallis and Dunn's multiple comparison tests. For chemotaxis assay, one-way analysis of variance with Sidak's multiple comparison. For qPCR time course, analysis of variance with Sidak's post hoc test and two-way analysis of variance to examine the overall treatment effect. For qPCR chemokine expression, unpaired $t$-test was used. For cytokine bead array assay, unpaired $t$-test with Welch's correction was used. Differences were considered significant for $P<0.05$.

\section{Results}

\section{Ductular Reaction Correlates with Fibrosis and Biliary Taurocholate in CFLD}

The DR, as assessed by CK7 expression, was markedly increased in CFLD and contained expanded reactive bile ducts, and both single LPCs and strings of biliary cells/ LPCs (Figure 1). The DR was mainly present in the periphery of portal tracts as irregular strands/chords of $\mathrm{CK} 7^{+}$ cells and as isolated single $\mathrm{CK} 7^{+}$LPCs in adjacent areas. This DR was increased in CFLD $(P<0.05)$, as well as in biliary atresia $(P=0.114)$ and idiopathic neonatal hepatitis $(P=0.016)$, versus controls (Figure $2 \mathrm{~A})$. When stratified for fibrosis stage, there was a highly significant positive correlation between CK7 staining and increasing fibrosis stage in CFLD (Spearman $r=0.59, P<0.0001$ ) (Figure 2B). Bile samples were available from 7 of the 60 children with CFLD. There was a positive statistical correlation between biliary taurocholate concentrations and the extent of the DR as assessed via CK7 quantification $(r=0.528, P=0.0321)$ (Figure 2C).

\section{Taurocholate Induces Biliary Differentiation of LPCs}

Because in CFLD, the extent of the DR was demonstrated to correlate with both fibrosis severity and biliary taurocholate levels, it was hypothesized that taurocholate may induce LPC biliary differentiation and the DR. To interrogate this hypothesis, the murine LPC line PIL-2 was treated with 0 to $300 \mu \mathrm{mol} / \mathrm{L}$ taurocholate for 4 days to establish the optimal conditions for all in vitro and ex vivo studies. Taurocholate induced a dose-dependent increase in mRNA expression of the cholangiocyte markers $C x 43$ (analysis of variance, $P<0.0001$ ) (Figure 3A) and $C k 19$ (analysis of variance, $P<0.0001$ ) (Figure 3B). A taurocholate concentration of $150 \mu \mathrm{mol} / \mathrm{L}$ was chosen for all subsequent experiments as has previously been described in in vitro studies, ${ }^{21,23}$ and also being consistent with previous observations in children with CFLD that displayed a mean biliary taurocholate concentration of $108 \mu \mathrm{mol} / \mathrm{L}$ versus $41 \mu \mathrm{mol} / \mathrm{L}$ in healthy controls. $^{21}$

PIL-2 cells were treated with $150 \mu \mathrm{mol} / \mathrm{L}$ taurocholate for 0 to 4 days, and markers of cholangiocyte differentiation were further assessed. Taurocholate induced a time-dependent increase in mRNA expression of cholangiocyte markers $C \times 43$ (analysis of variance, $P<0.0001$ ) (Figure $3 \mathrm{C}$ ), $C k 19$ (analysis 

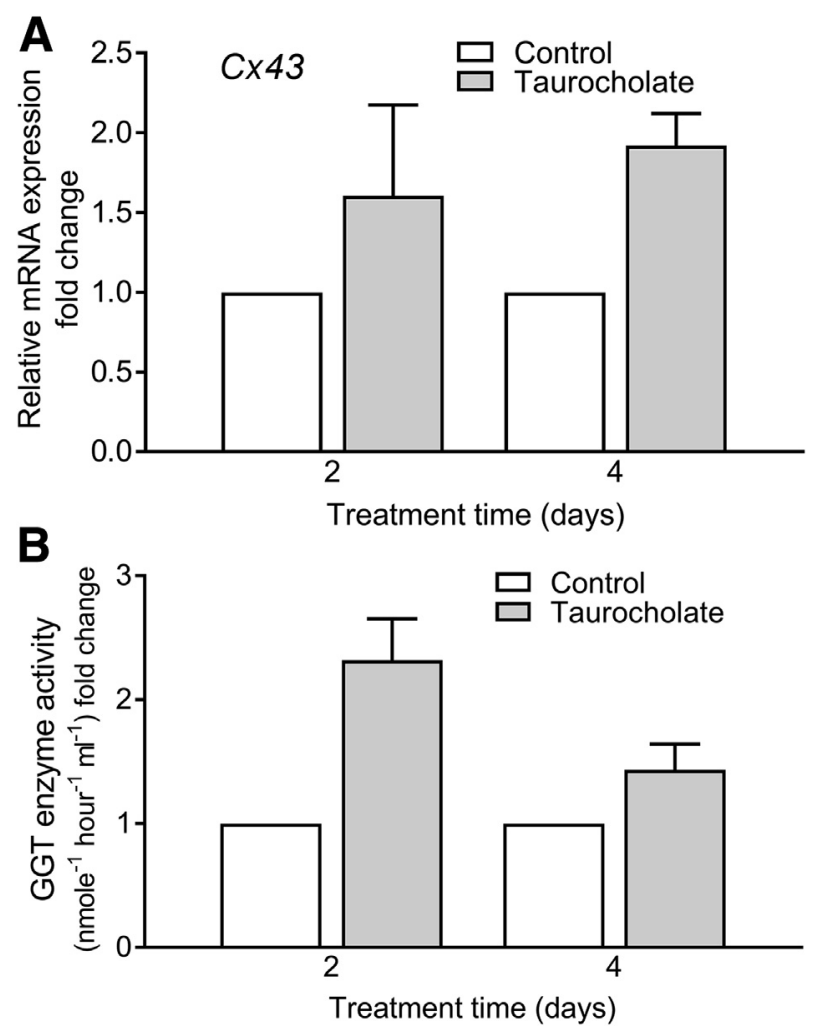

Figure 8 Effect of taurocholate in an ex vivo liver model. To demonstrate the potential physiological relevance of our in vitro observation, we used precision-cut liver slices treated with $150 \mu \mathrm{mol} / \mathrm{L}$ taurocholate for 4 days to demonstrate a time-dependent increase in mRNA expression of the cholangiocyte marker $C \times 43$ (analysis of variance, $P=0.0354)(A)$, as well as GGT enzyme activity normalized to tissue weight (analysis of variance, $P=0.0021)(B)$. Data are expressed means \pm SEM. $n=3$ replicates from 3 mice (A); $n=6$ replicates from 3 mice (B).

of variance, $P<0.0001$ ) (Figure 3D), Itgb4 (analysis of variance, $P<0.029$ ) (Figure 3E), and Ggtl (analysis of variance, $P<0.001$ ) (Figure $3 \mathrm{~F}$ ). Taurocholate treatment did not significantly alter expression of two other cholangiocyte markers, EpCam and Sox9 (data not shown).

Of interest, a concomitant decrease in mRNA expression of the master regulator of hepatic differentiation, $H n f 4 \alpha$ was observed (analysis of variance, $P=0.0255$ ) (Figure 4A). A second hepatocyte marker, albumin (Alb) showed no significant difference with taurocholate treatment (Figure 4B). Taken together, these results suggest that taurocholate augments the cholangiocytic differentiation of the LPC line PIL-2.

\section{LPC Proliferation Is Induced by Taurocholate}

Integral to the formation of the DR is the expansion of LPCs in chronic liver disease. To assess the potential effect of taurocholate on LPC proliferation, PIL-2 cells with and without $150 \mu \mathrm{mol} / \mathrm{L}$ taurocholate were subjected to an MTT cell proliferation assay every 24 hours for 1 to 4 days. Taurocholate induced a time-dependent increase in LPC proliferation (analysis of variance, $P=0.0003$ ) (Figure 5), which was most notable early, that is, after 1 to 2 days.

\section{Taurocholate Induces Differentiation of LPCs into} Functional Cholangiocytes

Although Figure 3 demonstrates that taurocholate induced the expression of cholangiocyte-associated genes in LPCs, an assessment of actual cholangiocyte function remained to be confirmed. Thus, we examined expression of proteins involved in various aspects of biliary cell function. We observed that CK19, a protein responsible for the structural integrity of cholangiocytes is significantly induced by taurocholate $(P=0.0006)$ (Figure $6, \mathrm{~A}$ and $\mathrm{B})$. Taurocholate also induced a significant $>2.5$-fold increase in SOX9 protein, a key transcriptional regulator of cholangiocyte differentiation and bile duct formation $(P=0.001)$ (Figure 6, A and C). Conversely, HNF4 $\alpha$ protein expression, a marker and transcriptional regulator of hepatocyte specification, was significantly decreased by taurocholate $(P=0.019)$ (Figure 6, A and D).

One key morphological characteristic of cholangiocytes is the presence of primary cilia with acetylated $\alpha$-tubulin being a key structural component. Western blot analysis revealed a significant induction of acetylated $\alpha$-tubulin protein expression in
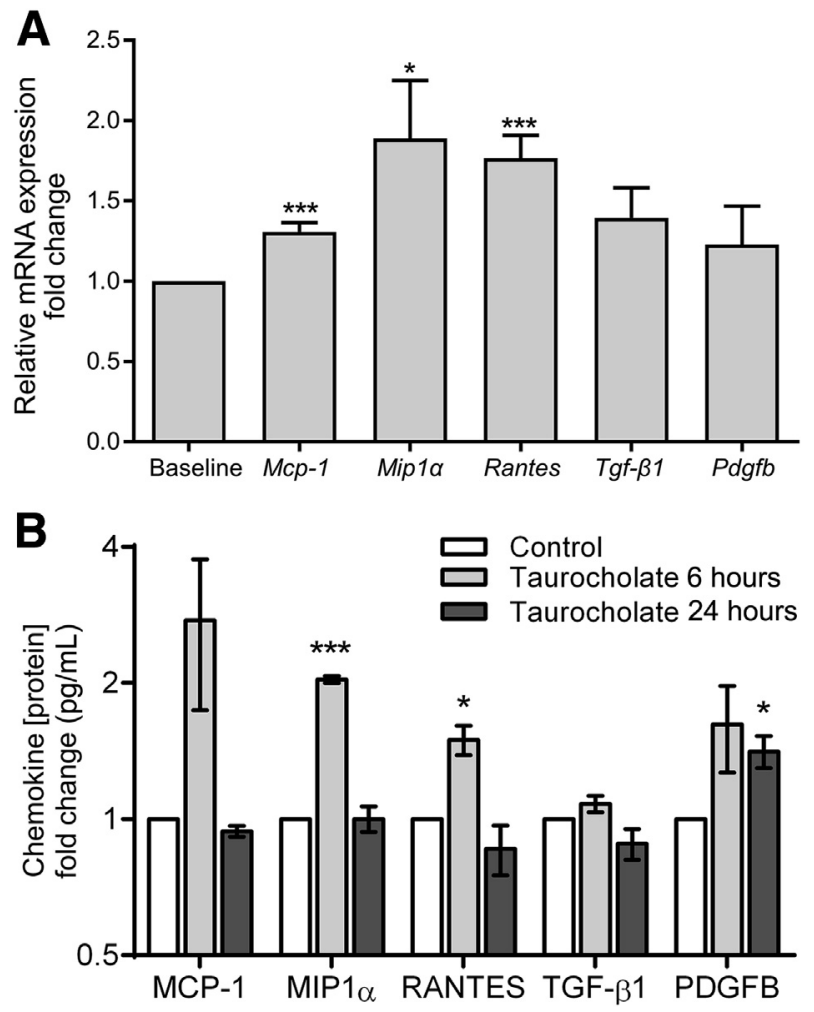

Figure 9 Profiling of hepatic chemokines expressed and secreted by liver progenitor cells after taurocholate treatment. A: Taurocholate induced a significant increase in Mcp-1, Mip 1 $\alpha$, and Rantes mRNA expression in PIL-2 cells at 6 hours. Statistical significance for each gene transcript was assessed using the $t$ test. B: Taurocholate treatment induced a significant increase in MIP1 $\alpha$ and RANTES protein release into the culture medium at 6 hours. MCP- 1 and PDGFB were also increased but this did not reach statistical significance. The effect of taurocholate was lost after 24 hours, except for the effect on PDGFB $(P=0.0153)$. TGF- $\beta$ protein release was not affected by taurocholate treatment. Data are expressed as means \pm SEM. ${ }^{*} P<0.05,{ }^{* * *} P<0.001$ versus control. 

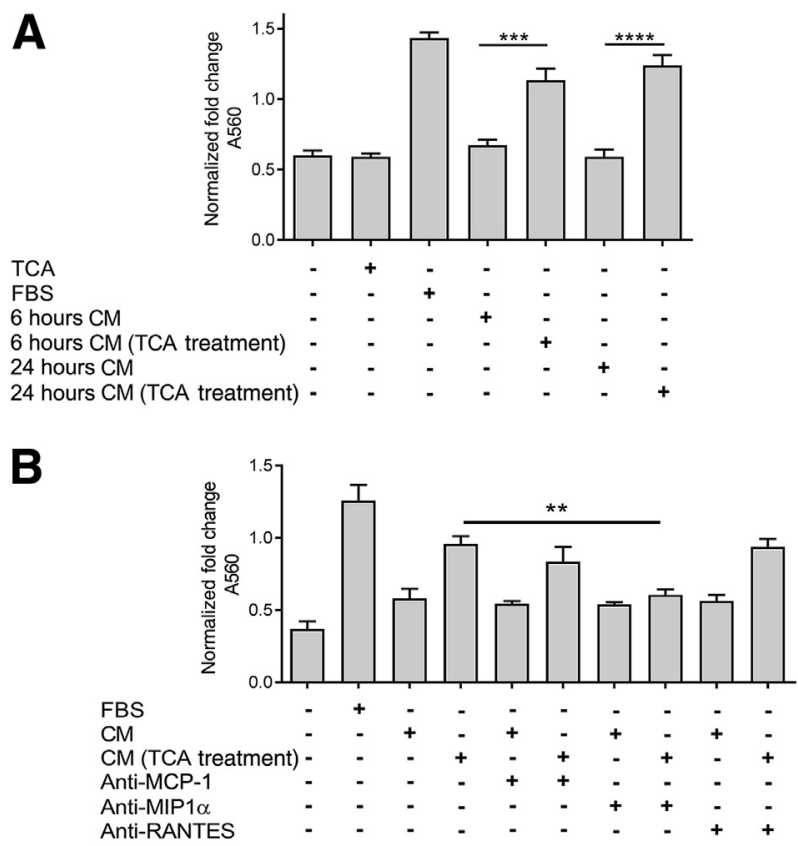

Figure 10 Treatment of liver progenitor cells with taurocholate induces hepatic stellate cell (HSC) chemotaxis. PIL-2 cells were treated with $150 \mu \mathrm{mol} / \mathrm{L}$ taurocholate for 6 or 24 hours, and conditioned medium from these cells was used in modified Boyden chambers to examine LX-2 chemotaxis after 24 hours. A: Treatment of LX-2 HSCs with conditioned medium from either 6 or 24 hours taurocholate-treated PIL-2 cells resulted in significant HSC chemotaxis across the Boyden chamber membranes. B: Chemotaxis of LX-2 cells induced by conditioned medium from 24 hours taurocholate-treated PIL-2 cells was inhibited by anti-MIP1 $\alpha$ antibody. Statistical significance was determined using analysis of variance with Sidak's multiple comparisons test performed for specific comparisons. Data are expressed as means \pm SEM. $n>4$ (A); $n=3$ (B). ${ }^{* *} P<0.01,{ }^{* * *} P<0.001$, and ${ }^{* * * *} P<0.0001$. A560, absorbance at $560 \mathrm{~nm} ;$ CM, conditioned medium; FBS, fetal bovine serum; TCA, taurocholate.

taurocholate-treated LPCs $(P=0.026)$ (Figure 6, A and E). Because acetylated $\alpha$-tubulin can also be found within other cellular structures such as microtubule networks, the cellular localization of acetylated $\alpha$-tubulin was further investigated using immunofluorescence of LPCs with and without taurocholate. Expression of acetylated $\alpha$-tubulin causes primary cilia to appear as discrete dots or lines, whereas microtubule networks form thin filament-meshed patterns. ${ }^{33}$ As can be seen in Figure $7 \mathrm{~A}$, taurocholate induced a marked increase in the number of acetylated $\alpha$-tubulin ${ }^{+}$primary cilia when compared to controls, with quantitation of the relative fluorescence showing a 2.4-fold increase $(P=0.022)$ (Figure 7B).

Another measure of functional LPC-cholangiocyte differentiation is the production of enzymatically active GGT, which is expressed and released by cholangiocytes within bile ducts. PIL-2 cells were treated with and without $150 \mu \mathrm{mol} / \mathrm{L}$ taurocholate for 1 to 4 days with conditioned medium removed for analysis every 24 hours. Taurocholate induced a significant time-dependent increase in GGT activity (analysis of variance, $P<0.0001$ ), with maximal production between days 3 to 4 (Figure 7C). At the conclusion of the experiment (day 4), this result remained highly significant when corrected for cellular protein concentration (Supplemental Figure S1).
The Effect of Taurocholate in ex Vivo Precision-Cut Liver Slices

To demonstrate potential physiological relevance of our in vitro observations, precision-cut liver slices from normal control mice, treated with and without $150 \mu \mathrm{mol} / \mathrm{L}$ taurocholate for up to 4 days, were examined. The hepatic mRNA expression of $C x 43$, as a representative cholangiocyte marker, was significantly increased in a time-dependent manner (analysis of variance, $P=0.0354$ ) (Figure 8A). Conditioned medium collected was assayed for GGT activity and normalized to liver slice wet weight. Taurocholate again induced a significant increase in GGT activity, peaking at day 2 (analysis of variance, $P=0.0021$ ) (Figure 8B).

\section{Chemokine Expression Induced by Taurocholate in LPCs}

PIL-2 cells treated with $150 \mu \mathrm{mol} / \mathrm{L}$ taurocholate showed significantly increased expression of MCP-1, MIP1 $\alpha$, and RANTES mRNA at 6 hours (Figure 9A). We also examined the gene expression of the profibrotic cytokine TGF- $\beta 1$ and HSC mitogen PDGFB, which both have HSC chemotactic potential. Although taurocholate induced increased expression of both TGF- $\beta 1$ and PDGFB, this did not reach statistical significance (Figure 9A)

Conditioned medium from PIL-2 cells with and without $150 \mu \mathrm{mol} / \mathrm{L}$ taurocholate for 6 hours or 24 hours was assessed for protein secretion of key hepatic chemokines. Rantes, Mcp$1, \operatorname{Mip} 1 \alpha, T g f-\beta 1$, and $P d g f b$ were all expressed constitutively by PIL- 2 cells. After 6 hours, taurocholate treatment resulted in a twofold increase in MIP1 $\alpha$ protein release $(P<0.0001)$, whereas RANTES and PDGFB increased by approximately 1.5-fold (Figure 9B). Taurocholate induced an increase in MCP-1 secretion; however, this did not reach statistical significance. By 24 hours, chemokine levels were indistinguishable from controls, except for PDGFB, which remained elevated in response to taurocholate $(P<0.05)$. No effect was observed on TGF- $\beta 1$ release.

\section{HSCs Migrate in Response to Chemokines Secreted by Taurocholate-Treated LPCs}

Chemotaxis of the LX-2 HSC line was significantly induced by conditioned medium from PIL-2 cells treated with taurocholate for either 6 hours $(P<0.001)$ or 24 hours $(P<0.01)$ (Figure 10A). Similar levels of chemotaxis were demonstrated using primary rat HSCs (data not shown). To determine the identity of chemokines responsible for this chemotaxis, conditioned medium was pretreated with neutralizing antibodies to various different chemokines. Chemotaxis was completely inhibited by anti-MIP1 $\alpha$ neutralizing antibody (nAb); however, anti-RANTES nAb had no effect (Figure 10B). Although chemotaxis of LX-2 cells was partially suppressed using anti-MCP-1 nAb, this did not reach statistical significance. 
A

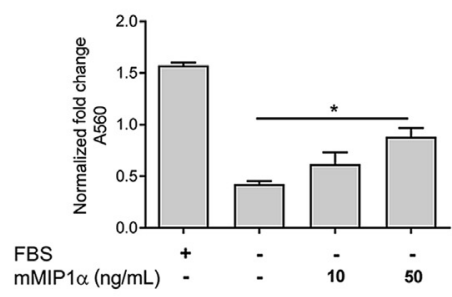

D

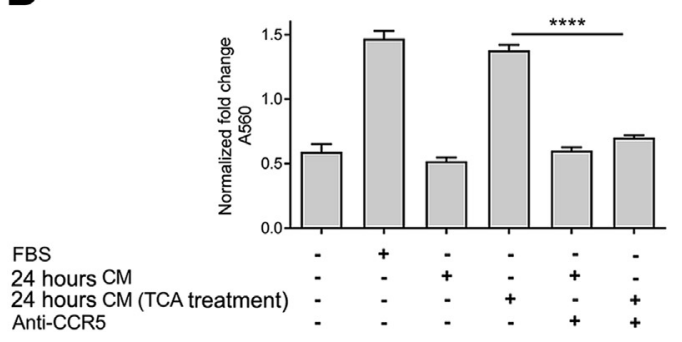

B

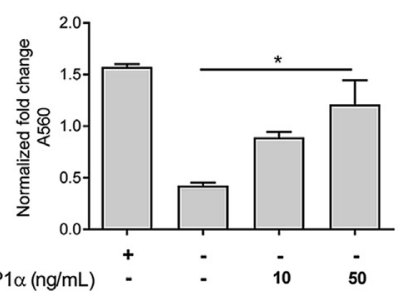

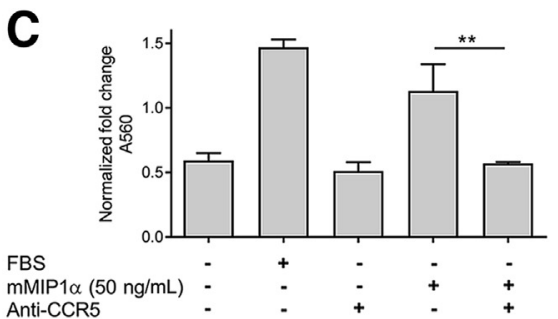

$\mathrm{mMIP} 1$
Anti-CCR5 $(50 \mathrm{ng} / \mathrm{mL})$ -

Figure 11 MIP1 $\alpha$ induces hepatic stellate cell (HSC) chemotaxis. A and B: LX-2 cells were placed in modified Boyden chambers with physiologically relevant concentrations of either murine recombinant MIP1 $\alpha(\mathbf{A})$ or human recombinant MIP1 $\alpha(\mathbf{B})$ and assessed for chemotactic potential. MIP1 $\alpha$ produced a significant dose-dependent increase in HSC chemotaxis (analysis of variance, $P=0.022$ and $P=0.0009$, respectively). Sidak's multiple comparisons test was performed for treatment comparison, C: The chemoattractive effect of murine recombinant MIP1 $\alpha$ was attenuated by pre-treating LX-2 cells with an anti-CCR5 neutralizing antibody. D: Pre-treatment of LX-2 cells with anti-CCR5 also attenuated chemotaxis in response to conditioned medium from 24-hour taurocholate-treated PIL-2 cells. Analysis of variance with Sidak's multiple comparisons test was performed for specific comparisons. Data are expressed as means \pm SEM. $n=3$ (A and $\mathbf{B}) ; n=4$ (C and D). ${ }^{*} P<0.05,{ }^{* *} P<0.01$, and ${ }^{* * *} P<0.0001$. A560, absorbance at $560 \mathrm{~nm} ; \mathrm{FBS}$, fetal bovine serum; TCA, taurocholate.

\section{HSCs Migrate in Response to MIP1 $\alpha$ Mediated by CCR5}

As shown in Figure 10B, chemotaxis of HSCs in response to conditioned medium from PIL-2 cells treated with taurocholate was inhibited by anti-MIP1 $\alpha$ nAb. To strengthen the case for the involvement of MIP1 $\alpha$ as a HSC chemotactic agent, a chemotaxis assay was performed on LX2 cells using either murine or human recombinant purified MIP1 $\alpha$. Both murine (analysis of variance, $P=0.022$ ) (Figure 11A) and human (analysis of variance, $P=0.0009$ ) (Figure 11B) MIP1 $\alpha$ produced a significant dose-dependent increase in HSC migration, approaching the effect observed with the positive control (FBS).

LX-2 cells were examined for the expression of both known major hepatic MIP1 $\alpha$ receptors, C-C chemokine receptor type 1 and 5 (CCR1 and CCR5). Using qPCR, expression of both Ccrl and $C c r 5$ was demonstrated, with $C c r 5$ showing higher mRNA levels versus Ccrl (Supplemental Figure S2). To investigate whether CCR5 was the major contributing receptor in HSC chemotaxis, LX-2 cells were pretreated with an anti-CCR5 nAb. This antibody effectively attenuated the migration of LX-2 HSCs in response to both recombinant murine MIP1 $\alpha$ (Figure 11C) and conditioned medium from PIL-2 cells treated with $150 \mu \mathrm{mol} / \mathrm{L}$ taurocholate (Figure 11D).

\section{DR Cells and LPCs Express Chemokines in Liver from Children with CFLD}

To assess the potential clinical relevance of taurocholateinduced chemokine expression demonstrated in in vitro and ex vivo studies, liver sections from patients with CFLD $(n=22)$ were examined for the cellular source of chemokines. Dual immunofluorescence confirmed that $\mathrm{CK}^{+}$DR cells, and single $\mathrm{CK}^{+}$LPCs, express MCP-1 (Figure 12A), RANTES (Figure 12B), and MIP1 $\alpha$ (Figure 13).

\section{Discussion}

The $\mathrm{DR}$ is proposed to be associated with the initiation of hepatic fibrosis in a number of chronic liver diseases. ${ }^{4,12,34,35}$ However, the precise mechanisms involved in its induction and indeed in the interactions between LPCs and HSCs, which may drive both the DR and fibrogenesis, remain to be elucidated. This histological process has been reported in many adult liver diseases, including chronic hepatitis $\mathrm{C},{ }^{12}$ alcoholic and nonalcoholic steatohepatitis, ${ }^{14,35}$ and genetic hemochromatosis. ${ }^{13}$ In these diseases, the DR correlates closely with severity of fibrosis and inflammation. ${ }^{34}$ However, the presence or role of the DR has not previously been investigated in children with CFLD. Here we show that the DR is indeed present in CFLD (and comparable to the DR present in more aggressive pediatric fibrosing cholestatic diseases such as biliary atresia ${ }^{36,37}$ ) and the extent of the DR significantly correlates with fibrosis staging in CFLD, suggesting that mechanisms regulating these two processes are interrelated.

Extensive investigation into the individual mechanisms of LPC and HSC activation ${ }^{38}$ have elucidated a role for many different soluble mediators in hepatic fibrosis. Understanding the interaction between LPCs and HSCs is of great importance for clarifying the contribution of these cells in mediating fibrogenesis and for designing therapeutic strategies aimed at reduction of hepatic fibrosis.

Bile salt retention is part of the proposed mechanism of injury and biliary fibrosis in CFLD, and we previously demonstrated that biliary/serum levels of the conjugated bile acid taurocholate are elevated in children with CFLD. ${ }^{21}$ In the present study, it was demonstrated that the extent of the DR correlates with biliary taurocholate concentration in children with CFLD and thus speculate a potential mechanistic link. To determine whether taurocholate plays a role in inducing the DR, both an LPC in vitro cell culture model and ex vivo 

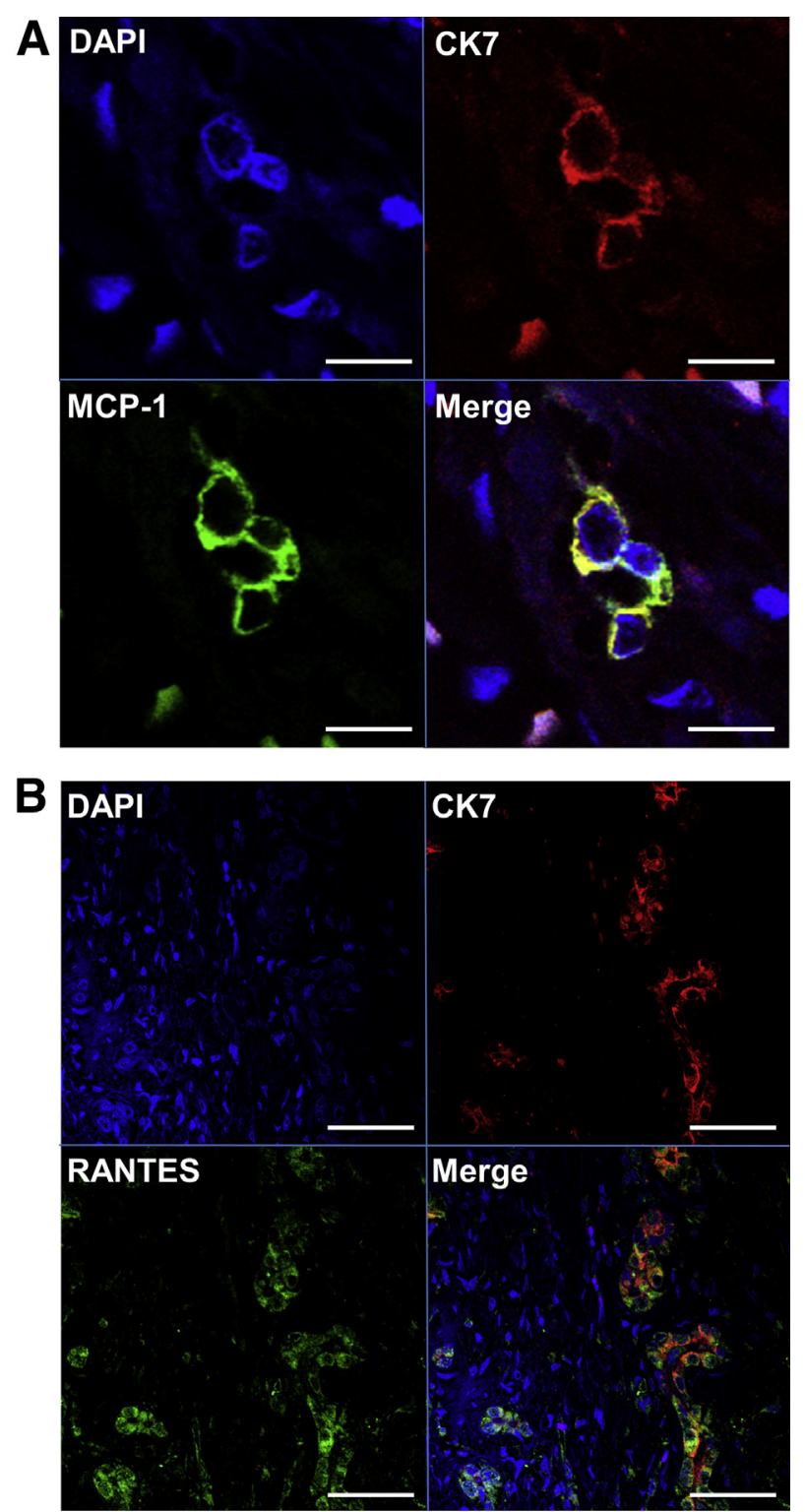

Figure 12 Cellular localization of MCP-1 and RANTES expression in liver from children with cystic fibrosis liver disease (CFLD). Dual immunofluorescence was performed on CFLD patients to demonstrate the colocalization of $\mathrm{CK}^{+}$ductular reaction cells with MCP-1 protein expression (A) and RANTES protein expression (B). Sections are shown with DAPI in blue, CK7 in red, and either MCP-1 or RANTES in green, with colocalization (merge). Scale bars: 20 $\mu \mathrm{m}(\mathrm{A}) ; 50 \mu \mathrm{m}($ B). Original magnification: $\times 63($ A) $; \times 40$ (B).

precision-cut liver slices were used, and a reductionist strategy was employed to examine the impact of taurocholate on three key events in the evolution of the DR: LPC proliferation, biliary differentiation of LPCs, and HSC chemotaxis.

In this study, it was demonstrated that taurocholate increased LPC proliferation in vitro, suggesting that taurocholate may play a role in enhancing LPC expansion as part of the DR in CFLD. This observation is supported by studies from Clouzeau-Girard et $\mathrm{al}^{39}$ showing that taurocholate leads to uncharacterized cell proliferation around the portal tracts in ex vivo liver slices. Our data are also consistent with the observation that feeding taurocholate to rats increases cholangiocyte numbers,${ }^{40}$ although this study did not distinguish whether these were mature adult cholangiocytes or derived from LPCs.

The biliary differentiation of LPCs and subsequent formation of reactive bile ductular structures appear to be an important component of DR development. A significant increase in expression of the cholangiocyte genes $C k 19, C x 43$, Itgb4, and Ggtl was demonstrated in response to taurocholate treatment of LPCs. Conversely, the hepatocyte lineage marker $H n f 4 \alpha$ was decreased, with albumin expression unchanged. This in vitro
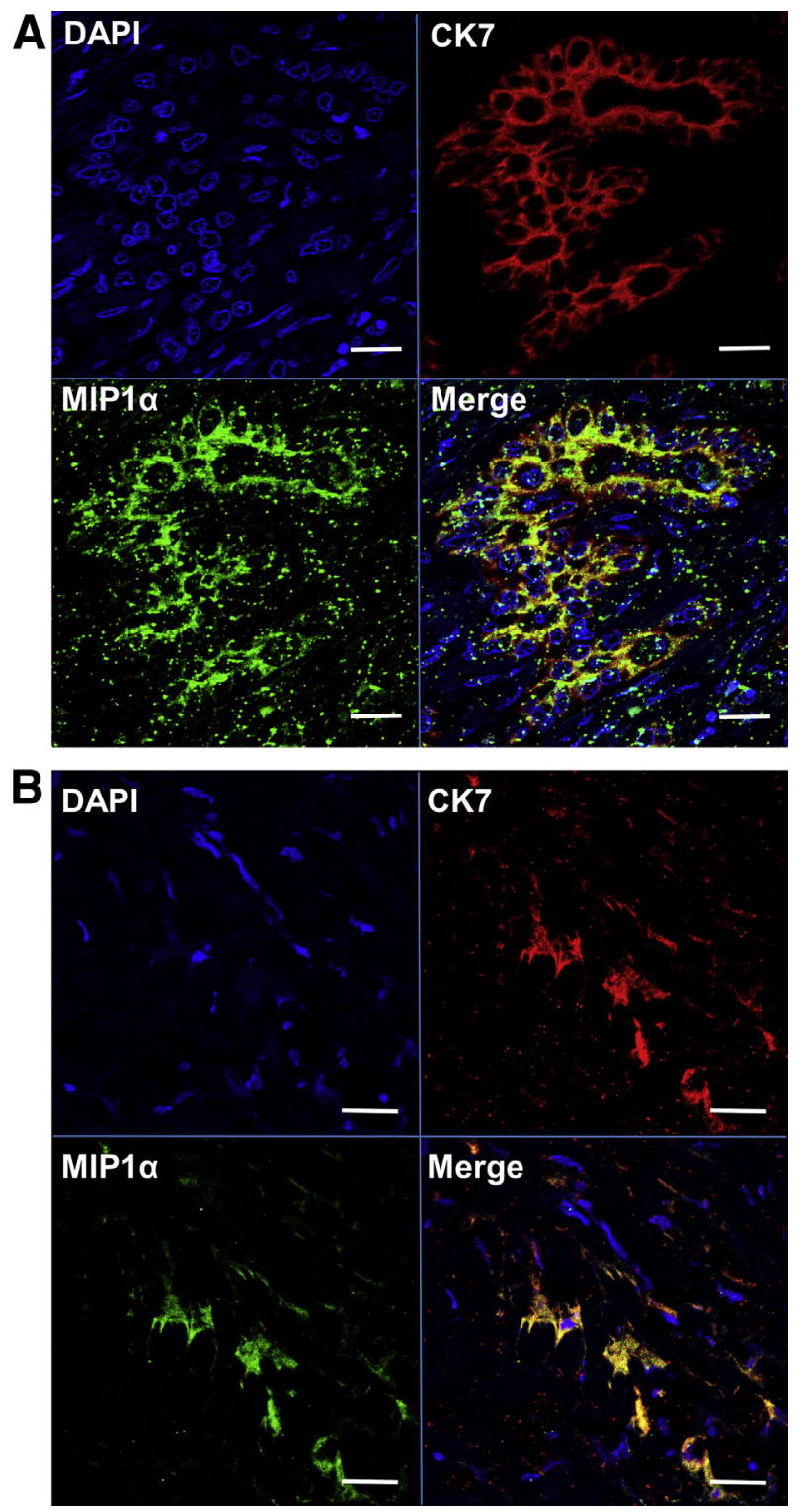

Figure 13 Cellular localization of MIP1 $\alpha$ expression in liver from children with cystic fibrosis liver disease (CFLD). Dual immunofluorescence was performed on CFLD patients for the association of MIP1 $\alpha$ protein expression with clusters of $\mathrm{CK}^{+}$ductular reaction cells (A) and individual $\mathrm{CK} 7^{+}$liver progenitor cells (B). Sections are shown with DAPI in blue, CK7 in red, and $\mathrm{M} 1 \mathrm{P} \alpha$ in green with colocalization (merge). Scale bars $=20$ $\mu \mathrm{m}$. Original magnification: $\times 40,1.4 \mathrm{zoom}(\mathrm{A}) ; \times 63(\mathbf{B})$. 


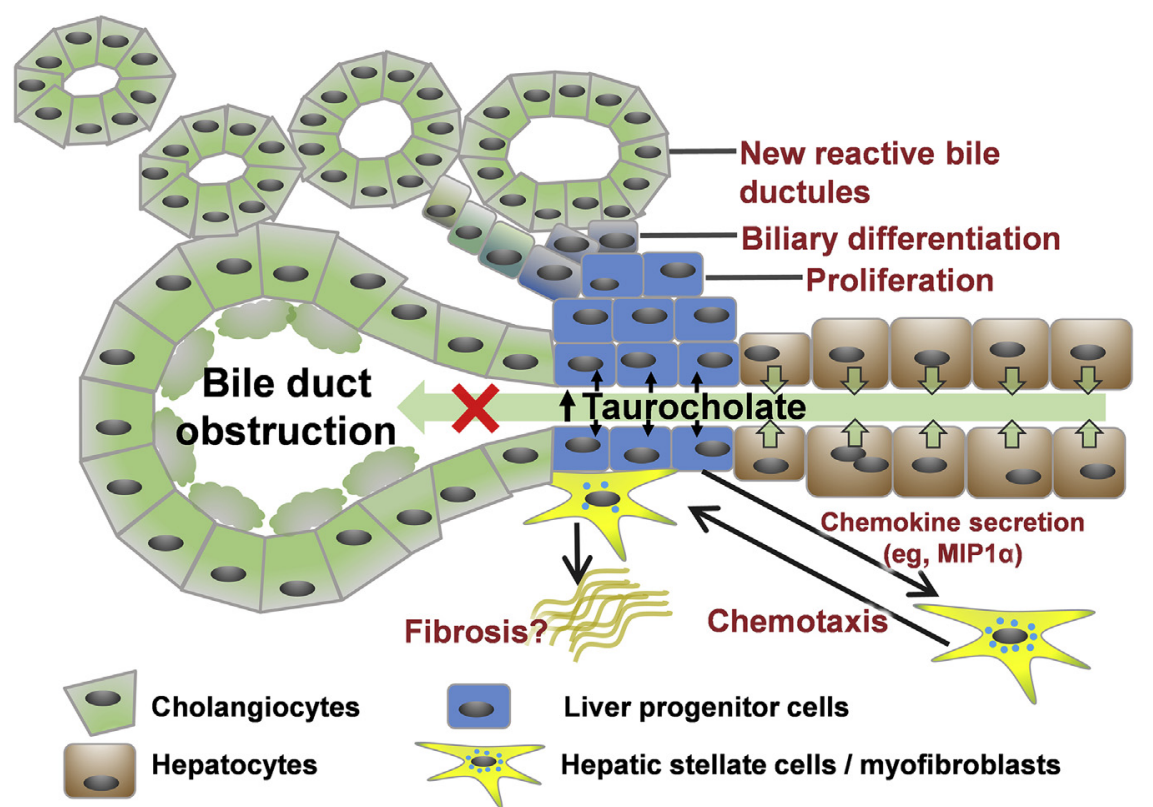

Figure 14 Proposed model for taurocholateinduced ductular reaction (DR) and fibrogenesis in children with cystic fibrosis liver disease. The cystic fibrosis transmembrane conductance regulator (CFTR) defect results in obstruction of the intrahepatic bile ducts (red $\mathbf{X}$ ). This obstruction elevates biliary taurocholate levels, which drives liver progenitor cell (LPC) proliferation and biliary/ cholangiocyte differentiation as part of the DR. In response to increased taurocholate, LPCs secrete chemokines that attract hepatic stellate cells (HSCs)/myofibroblasts (and likely other immune/ inflammatory cells) to the LPC niche and/or the region of DR development. Cell-cell contact between LPCS and recruited HSCs may result in activation of HSCs and subsequent fibrogenesis. result may be consistent with LPC differentiation that occurs during the DR in vivo and provides one potential mechanism for induction of the DR in pediatric cholestatic liver diseases such as CFLD. Further supporting this concept, it was demonstrated that taurocholate induced functional cholangiocyte differentiation, evidenced through the increased expression of acetylated $\alpha$ tubulin, CK19, and SOX9 protein, the increased numbers of LPCs elaborating primary cilia, as well as the secretion of enzymatically active GGT in vitro. The effect of taurocholate on cholangiocyte function was further confirmed in ex vivo precision-cut liver slices, showing induced expression of $C x 43$ mRNA and secretion of active GGT.

In addition, this study has demonstrated that taurocholateexposed LPCs secrete a number of chemokines including MCP-1, MIP1 $\alpha$, RANTES, and PDGFB; however, HSC chemotaxis in response to taurocholate-treated LPC conditioned medium appears to be principally due to MIP1 $\alpha$. Neutralizing antibodies to either MIP1 $\alpha$ in LPC conditioned medium or the MIP1 $\alpha$ receptor CCR5 on HSCs attenuated taurocholate-treated LPC-induced HSC chemotaxis. Thus, we propose that MIP1 $\alpha$ derived from bile acid-exposed LPCs may recruit HSCs (via CCR5) during the DR and aid in the initiation of hepatic fibrosis in CFLD. We did not demonstrate that RANTES aided in the chemoattraction of HSCs. Neutralization of MCP-1 resulted in a limited inhibition of HSC chemotaxis, however this did not reach statistical significance due to biological variability of the data. RANTES and MCP-1 may induce recruitment of other cells to the LPC niche as part of the fibrogenic process such as additional LPCs or inflammatory cells, as we previously described. ${ }^{21,41}$ Migration of HSCs toward LPCs, as well as HSC activation, could explain why fibrosis begins in periportal regions of the liver, where there is decreased bile flow through bile ducts, and thus increased accumulation of hydrophobic bile acids. ${ }^{19}$ This pattern of chemokine expression upon in vitro taurocholate treatment may be indicative of the specific role of LPCs in generating a microenvironment that aids in the activation of HSCs. In the current study, immunofluorescence revealed that MCP-1, RANTES, and MIP1 $\alpha$ are all expressed by DR cells and $\mathrm{CK}^{+}{ }^{+}$LPCs in liver from children with CFLD, providing in vivo evidence validating our in vitro observations.

HSC activation is also influenced by other cell types present during chronic liver injury and inflammation, because the LPC niche harbors immune cells including liver macrophages, which also secrete MCP-1, MMPs, TIMPS ${ }^{42,43}$ and chemokines. The downstream chemoattractive effect caused by exposure of LPCs to increased levels of taurocholate appears likely to recruit HSCs into the LPC niche and places these two cell types within close proximity and potentially in direct contact. Supporting this, activated HSCs have been observed adjacent to LPCs in various mouse model of fibrosis, ${ }^{33,41,44}$ as well as in human liver diseases, ${ }^{13,45}$ demonstrating recruitment of each cell type toward the other during fibrosis. Various studies have also suggested that membrane contact (and cross talk) between LPCs and HSCs is a key mediator of fibrogenesis. ${ }^{41,46,47}$ In this context, our previous work showed that HSCs treated with the TNF superfamily member, lymphotoxin- $\beta$, induces NF- $\kappa \mathrm{B}$ signaling, up-regulating chemotaxis-associated factors such as RANTES and ICAM-1, and aiding in LPC and inflammatory cell recruitment. ${ }^{41}$ Because HSCs express the lymphotoxin- $\beta$ receptor on their cell surface, and lymphotoxin- $\beta$ is a membranebound ligand on LPCs, this suggests that direct cell-cell contact between LPCs and HSCs may be required to initiate chemokine expression. ${ }^{41}$ Adding to the complexity of this system, high concentrations of taurocholate have also been 
shown to induce inflammatory gene expression in hepatocytes, as well as cytokine/chemokine secretion, that may also lead to HSC recruitment and activation. ${ }^{21,22}$ The present study suggests that the DR precedes fibrosis. However, there is an alternate hypothesis stating that fibrosis precedes the DR, and there is some evidence to support this in animal studies. ${ }^{48}$ It is also possible that the two processes may be injury context-specific thus further investigations are warranted to fully elucidate the temporal nature of LPC niche development. In addition to HSCs, portal fibroblasts may also contribute to CFLD. However, whereas previous studies have shown that both activated HSCs and myofibroblasts produce collagen in this disease, ${ }^{26}$ the role of myofibroblasts derived from portal fibroblasts and indeed the potential recruitment by, and interaction between, these cells and LPCs has not been previously investigated.

\section{Conclusions}

In conclusion, this study has shown that the DR is present in CFLD and is correlated with biliary taurocholate levels, as well as increasing hepatic fibrosis severity. Thus, we propose that the following model may in part help to explain the pathogenesis of CFLD (Figure 14). In this model, the CFTR defect causes thickened mucous secretions and obstruction of the intrahepatic bile ducts. This obstruction elevates biliary levels of bile salts such as taurocholate in the vicinity of LPCs, induced as a result of hepatic injury and potentially compromised hepatocyte replication associated with the chronic nature of liver injury in CFLD. In response to supraphysiological levels of bile salts, LPCs first undergo proliferation followed by differentiation toward cholangiocytes as part of the DR. Also, in response to altered bile salt levels, LPCs secrete chemokines, including MCP-1, MIP1 $\alpha$, and RANTES, and this likely attracts HSCs and other immune/inflammatory cells to the LPC niche. Cell-cell contact between LPCs and recruited HSCs may result in activation of HSCs and subsequent fibrogenesis, at least in part via interaction between the HSC lymphotoxin- $\beta$ receptor via cognate ligands on LPCs, with further inflammatory niche chemotaxis, as we previously described. ${ }^{41}$ Increased understanding of the role of hydrophobic bile acids in CFLD and their impact on the LPC niche, cellular cross talk with HSCs, and induction of the DR will provide important new knowledge of clinical relevance, which may aid in the development of targeted therapeutic strategies to reduce fibrosis in CFLD and potentially in other pediatric cholestatic disorders.

\section{Acknowledgments}

We thank Clay Winterford, Nigel Waterhouse, Tam Hong Nguyen, and Fernando Guimaraes (QIMR Berghofer Medical Research Institute) for technical support, and Prof.
George Yeoh (University of Western Australia) for his gift of the PIL-2 murine liver progenitor cell line.

\section{Supplemental Data}

Supplemental material for this article can be found at https://doi.org/10.1016/j.ajpath.2017.08.024.

\section{References}

1. Colombo C, Battezzati PM, Crosignani A, Morabito A, Costantini D, Padoan R, Giunta A: Liver disease in cystic fibrosis: a prospective study on incidence, risk factors, and outcome. Hepatology 2002, 36: 1374-1382

2. Lindblad A, Hultcrantz R, Strandvik B: Bile-duct destruction and collagen deposition: a prominent ultrastructural feature of the liver in cystic fibrosis. Hepatology 1992, 16:372-381

3. Lindblad A, Glaumann H, Strandvik B: Natural history of liver disease in cystic fibrosis. Hepatology 1999, 30:1151-1158

4. Roskams TA, Theise ND, Balabaud C, Bhagat G, Bhathal PS, BioulacSage P, Brunt EM, Crawford JM, Crosby HA, Desmet V, Finegold MJ, Geller SA, Gouw AS, Hytiroglou P, Knisely AS, Kojiro M, Lefkowitch JH, Nakanuma Y, Olynyk JK, Park YN, Portmann B, Saxena R, Scheuer PJ, Strain AJ, Thung SN, Wanless IR, West AB: Nomenclature of the finer branches of the biliary tree: canals, ductules, and ductular reactions in human livers. Hepatology 2004, 39: $1739-1745$

5. Williams MJ, Clouston AD, Forbes SJ: Links between hepatic fibrosis, ductular reaction, and progenitor cell expansion. Gastroenterology 2014, 146:349-356

6. Theise ND, Saxena R, Portmann BC, Thung SN, Yee H, Chiriboga L, Kumar A, Crawford JM: The canals of Hering and hepatic stem cells in humans. Hepatology 1999, 30:1425-1433

7. Köhn-Gaone J, Gogoi-Tiwari J, Ramm GA, Olynyk JK, TirnitzParker JE: The role of liver progenitor cells during liver regeneration, fibrogenesis, and carcinogenesis. Am J Physiol Gastrointest Liver Physiol 2016, 310:G143-G154

8. Lu WY, Bird TG, Boulter L, Tsuchiya A, Cole AM, Hay T, Guest RV, Wojtacha D, Man TY, Mackinnon A, Ridgway RA, Kendall T, Williams MJ, Jamieson T, Raven A, Hay DC, Iredale JP, Clarke AR, Sansom OJ, Forbes SJ: Hepatic progenitor cells of biliary origin with liver repopulation capacity. Nat Cell Biol 2015, 17:971-983

9. Burt AD, MacSween RN: Bile duct proliferation-its true significance? Histopathology 1993, 23:599-602

10. Desmet VJ: Ductal plates in hepatic ductular reactions. Hypothesis and implications. I. Types of ductular reaction reconsidered. Virchows Arch 2011, 458:251-259

11. Roskams T, van den Oord JJ, De Vos R, Desmet VJ: Neuroendocrine features of reactive bile ductules in cholestatic liver disease. Am J Pathol 1990, 137:1019-1025

12. Clouston AD, Powell EE, Walsh MJ, Richardson MM, Demetris AJ, Jonsson JR: Fibrosis correlates with a ductular reaction in hepatitis C: roles of impaired replication, progenitor cells and steatosis. Hepatology 2005, 41:809-818

13. Wood MJ, Gadd VL, Powell LW, Ramm GA, Clouston AD: Ductular reaction in hereditary hemochromatosis: the link between hepatocyte senescence and fibrosis progression. Hepatology 2014, 59:848-857

14. Roskams T, Yang SQ, Koteish A, Durnez A, DeVos R, Huang X, Achten R, Verslype C, Diehl AM: Oxidative stress and oval cell accumulation in mice and humans with alcoholic and nonalcoholic fatty liver disease. Am J Pathol 2003, 163:1301-1311

15. Prakoso E, Tirnitz-Parker JE, Clouston AD, Kayali Z, Lee A, Gan EK, Ramm GA, Kench JG, Bowen DG, Olynyk JK, McCaughan GW, Shackel NA: Analysis of the intrahepatic ductular reaction and 
progenitor cell responses in hepatitis C virus recurrence after liver transplantation. Liver Transpl 2014, 20:1508-1519

16. Fabris L, Cadamuro M, Guido M, Spirli C, Fiorotto R, Colledan M, Torre G, Alberti D, Sonzogni A, Okolicsanyi L, Strazzabosco M: Analysis of liver repair mechanisms in Alagille syndrome and biliary atresia reveals a role for notch signaling. Am J Pathol 2007, 171:641-653

17. Omenetti A, Bass LM, Anders RA, Clemente MG, Francis H, Guy CD, McCall S, Choi SS, Alpini G, Schwarz KB, Diehl AM, Whitington PF: Hedgehog activity, epithelial-mesenchymal transitions, and biliary dysmorphogenesis in biliary atresia. Hepatology 2011, 53:1246-1258

18. Thomas C, Pellicciari R, Pruzanski M, Auwerx J, Schoonjans K: Targeting bile-acid signalling for metabolic diseases. Nat Rev Drug Discov 2008, 7:678-693

19. Smith JL, Lewindon PJ, Hoskins AC, Pereira TN, Setchell KD, O'Connell NC, Shepherd RW, Ramm GA: Endogenous ursodeoxycholic acid and cholic acid in liver disease due to cystic fibrosis. Hepatology 2004, 39:1673-1682

20. Marschall HU, Wagner M, Bodin K, Zollner G, Fickert P, Gumhold J, Silbert D, Fuchsbichler A, Sjovall J, Trauner M: Fxr(-/-) mice adapt to biliary obstruction by enhanced phase I detoxification and renal elimination of bile acids. J Lipid Res 2006, 47:582-592

21. Ramm GA, Shepherd RW, Hoskins AC, Greco SA, Ney AD, Pereira TN, Bridle KR, Doecke JD, Meikle PJ, Turlin B, Lewindon PJ: Fibrogenesis in pediatric cholestatic liver disease: role of taurocholate and hepatocyte-derived monocyte chemotaxis protein-1 in hepatic stellate cell recruitment. Hepatology 2009, 49:533-544

22. Allen K, Jaeschke H, Copple BL: Bile acids induce inflammatory genes in hepatocytes: a novel mechanism of inflammation during obstructive cholestasis. Am J Pathol 2011, 178:175-186

23. Lamireau T, Zoltowska M, Levy E, Yousef I, Rosenbaum J, Tuchweber B, Desmouliere A: Effects of bile acids on biliary epithelial cells: proliferation, cytotoxicity, and cytokine secretion. Life Sci 2003, 72:1401-1411

24. Kruglov EA, Nathanson RA, Nguyen T, Dranoff JA: Secretion of MCP-1/CCL2 by bile duct epithelia induces myofibroblastic transdifferentiation of portal fibroblasts. Am J Physiol Gastrointest Liver Physiol 2006, 290:G765-G771

25. Marra F, Romanelli RG, Giannini C, Failli P, Pastacaldi S, Arrighi MC, Pinzani M, Laffi G, Montalto P, Gentilini P: Monocyte chemotactic protein-1 as a chemoattractant for human hepatic stellate cells. Hepatology 1999, 29:140-148

26. Lewindon PJ, Pereira TN, Hoskins AC, Bridle KR, Williamson RM, Shepherd RW, Ramm GA: The role of hepatic stellate cells and transforming growth factor-beta(1) in cystic fibrosis liver disease. Am J Pathol 2002, 160:1705-1715

27. Lewindon PJ, Shepherd RW, Walsh MJ, Greer RM, Williamson R, Pereira TN, Frawley K, Bell SC, Smith JL, Ramm GA: Importance of hepatic fibrosis in cystic fibrosis and the predictive value of liver biopsy. Hepatology 2011, 53:193-201

28. Pereira TN, Lewindon PJ, Smith JL, Murphy TL, Lincoln DJ, Shepherd RW, Ramm GA: Serum markers of hepatic fibrogenesis in cystic fibrosis liver disease. J Hepatol 2004, 41:576-583

29. Dumble ML, Croager EJ, Yeoh GC, Quail EA: Generation and characterization of p53 null transformed hepatic progenitor cells: oval cells give rise to hepatocellular carcinoma. Carcinogenesis 2002, 23:435-445

30. Alley MC, Scudiero DA, Monks A, Hursey ML, Czerwinski MJ, Fine DL, Abbott BJ, Mayo JG, Shoemaker RH, Boyd MR: Feasibility of drug screening with panels of human tumor cell lines using a microculture tetrazolium assay. Cancer Res 1988, 48:589-601

31. Laemmli UK: Cleavage of structural proteins during the assembly of the head of bacteriophage T4. Nature 1970, 227:680-685
32. Gobert GN, Nawaratna SK, Harvie M, Ramm GA, McManus DP: An ex vivo model for studying hepatic schistosomiasis and the effect of released protein from dying eggs. PLoS Negl Trop Dis 2015, 9:e0003760

33. Grzelak CA, Martelotto LG, Sigglekow ND, Patkunanathan B, Ajami K, Calabro SR, Dwyer BJ, Tirnitz-Parker JE, Watkins DN, Warner FJ, Shackel NA, McCaughan GW: The intrahepatic signalling niche of hedgehog is defined by primary cilia positive cells during chronic liver injury. J Hepatol 2014, 60:143-151

34. Lowes KN, Brennan BA, Yeoh GC, Olynyk JK: Oval cell numbers in human chronic liver diseases are directly related to disease severity. Am J Pathol 1999, 154:537-541

35. Richardson MM, Jonsson JR, Powell EE, Brunt EM, NeuschwanderTetri BA, Bhathal PS, Dixon JB, Weltman MD, Tilg H, Moschen AR, Purdie DM, Demetris AJ, Clouston AD: Progressive fibrosis in nonalcoholic steatohepatitis: association with altered regeneration and a ductular reaction. Gastroenterology 2007, 133:80-90

36. Hartley JL, Davenport M, Kelly DA: Biliary atresia. Lancet 2009, 374: 1704-1713

37. Gouw AS, Clouston AD, Theise ND: Ductular reactions in human liver: diversity at the interface. Hepatology 2011, 54:1853-1863

38. Bird TG, Lorenzini S, Forbes SJ: Activation of stem cells in hepatic diseases. Cell Tissue Res 2008, 331:283-300

39. Clouzeau-Girard H, Guyot C, Combe C, Moronvalle-Halley V, Housset C, Lamireau T, Rosenbaum J, Desmouliere A: Effects of bile acids on biliary epithelial cell proliferation and portal fibroblast activation using rat liver slices. Lab Invest 2006, 86:275-285

40. Alpini G, Ueno Y, Glaser SS, Marzioni M, Phinizy JL, Francis H, Lesage G: Bile acid feeding increased proliferative activity and apical bile acid transporter expression in both small and large rat cholangiocytes. Hepatology 2001, 34:868-876

41. Ruddell RG, Knight B, Tirnitz-Parker JE, Akhurst B, Summerville L, Subramaniam VN, Olynyk JK, Ramm GA: Lymphotoxin-beta receptor signaling regulates hepatic stellate cell function and wound healing in a murine model of chronic liver injury. Hepatology 2009, 49:227-239

42. Duffield JS, Forbes SJ, Constandinou CM, Clay S, Partolina M, Vuthoori S, Wu S, Lang R, Iredale JP: Selective depletion of macrophages reveals distinct, opposing roles during liver injury and repair. J Clin Invest 2005, 115:56-65

43. Olynyk JK, Yeoh GC, Ramm GA, Clarke SL, Hall PM, Britton RS, Bacon BR, Tracy TF: Gadolinium chloride suppresses hepatic oval cell proliferation in rats with biliary obstruction. Am J Pathol 1998, 152: 347-352

44. Köhn-Gaone J, Dwyer BJ, Grzelak CA, Miller G, Shackel NA, Ramm GA, McCaughan GW, Elsegood CL, Olynyk JK, TirnitzParker JE: Divergent inflammatory, fibrogenic, and liver progenitor cell dynamics in two common mouse models of chronic liver injury. Am J Pathol 2016, 186:1762-1774

45. Gadd VL, Melino M, Roy S, Horsfall L, O'Rourke P, Williams MR, Irvine KM, Sweet MJ, Jonsson JR, Clouston AD, Powell EE: Portal, but not lobular, macrophages express matrix metalloproteinase-9: association with the ductular reaction and fibrosis in chronic hepatitis C. Liver Int 2013, 33:569-579

46. Dwyer BJ, Olynyk JK, Ramm GA, Tirnitz-Parker JE: TWEAK and LT $\beta$ signaling during chronic liver disease. Front Immunol 2014, 5:39

47. Tirnitz-Parker JE, Olynyk JK, Ramm GA: Role of TWEAK in coregulating liver progenitor cell and fibrogenic responses. Hepatology 2014, 59:1198-1201

48. Van Hul NK, Abarca-Quinones J, Sempoux C, Horsmans Y, Leclercq IA: Relation between liver progenitor cell expansion and extracellular matrix deposition in a CDE-induced murine model of chronic liver injury. Hepatology 2009, 49:1625-1635 